\title{
Interindividual Variation in CYP3A Activity Influences Lapatinib Bioactivation ${ }^{[}$
}

\author{
Jennifer E. Bissada, Vivian Truong, Arsany A. Abouda, Kahari J. Wines, Rachel D. Crouch, \\ and (1) Klarissa D. Jackson
}

\begin{abstract}
Department of Pharmaceutical Sciences, Lipscomb University College of Pharmacy and Health Sciences, Nashville, Tennessee (J.E.B., V.T., A.A.A., K.J.W., R.D.C., K.D.J.); Department of Pharmacology, Vanderbilt University School of Medicine, Nashville, Tennessee (R.D.C., K.D.J.); and Division of Pharmacotherapy and Experimental Therapeutics, UNC Eshelman School of Pharmacy, University of North Carolina at Chapel Hill, Chapel Hill, North Carolina (K.D.J.)
\end{abstract}

Received July 23, 2019; accepted September 3, 2019

\section{ABSTRACT}

Lapatinib is a dual tyrosine kinase inhibitor associated with rare but potentially severe idiosyncratic hepatotoxicity. We have previously shown that cytochromes P450 CYP3A4 and CYP3A5 quantitatively contribute to lapatinib bioactivation, leading to formation of a reactive, potentially toxic quinone imine. CYP3A5 is highly polymorphic; however, the impact of CYP3A5 polymorphism on lapatinib metabolism has not been fully established. The goal of this study was to determine the effect of CYP3A5 genotype and individual variation in CYP3A activity on the metabolic activation of lapatinib using human-relevant in vitro systems. Lapatinib metabolism was examined using CYP3A5-genotyped human liver microsomes and cryopreserved human hepatocytes. CYP3A and CYP3A5-selective activities were measured in liver tissues using probe substrates midazolam and T-5 (T-1032), respectively, to evaluate the correlation between enzymatic activity and lapatinib metabolite formation. Drug metabolites were measured by high-performance liquid chromatographytandem mass spectrometry. Further, the relative contributions of CYP3A4 and CYP3A5 to lapatinib $O$-debenzylation were estimated using selective chemical inhibitors of CYP3A. The results from this study demonstrated that lapatinib O-debenzylation and quinone imine-GSH conjugate

\section{Introduction}

Lapatinib was the first orally active small-molecule dual inhibitor of epidermal growth factor receptor and human epidermal growth factor receptor 2 (HER2) approved (2007) for the treatment of advanced or metastatic HER2-positive breast cancer (Rusnak et al., 2001; Lackey, 2006; Moy et al., 2007). Clinical use of lapatinib is limited because of severe, sometimes fatal idiosyncratic hepatotoxicity (Gomez et al., 2008; Moy et al., 2009; Peroukides et al., 2011; Spraggs et al., 2011; Azim et al., 2013; Goss et al., 2013). Lapatinib-induced liver injury is thought

This research is funded by the National Cancer Institute of the National Institutes of Health (K01CA190711). Research reported here is solely the responsibility of the authors and does not necessarily represent the official views of the NIH.

https://doi.org/10.1124/dmd.119.088823.

S This article has supplemental material available at dmd.aspetjournals.org. formation were highly correlated with hepatic CYP3A activity, as measured by midazolam 1'-hydroxylation. CYP3A4 played a dominant role in lapatinib bioactivation in all liver tissues evaluated. The CYP3A5 contribution to lapatinib bioactivation varied by individual donor and was dependent on CYP3A5 genotype and activity. CYP3A5 contributed approximately $20 \%-42 \%$ to lapatinib $O$-debenzylation in livers from CYP3A5 expressers. These findings indicate that individual CYP3A activity, not CYP3A5 genotype alone, is a key determinant of lapatinib bioactivation and likely influences exposure to reactive metabolites.

\section{SIGNIFICANCE STATEMENT}

This study is the first to examine the effect of CYP3A5 genotype, total CYP3A activity, and CYP3A5-selective activity on lapatinib bioactivation in individual human liver tissues. The results of this investigation indicate that lapatinib bioactivation via oxidative O-debenzylation is highly correlated with total hepatic CYP3A activity, and not CYP3A5 genotype alone. These findings provide insight into the individual factors, namely, CYP3A activity, that may affect individual exposure to reactive, potentially toxic metabolites of lapatinib.

ABBREVIATIONS: AO, aldehyde oxidase; DMSO, dimethylsulfoxide; HER2, human epidermal growth factor receptor 2; KHB, Krebs-Henseleit buffer; LC-MS/MS, liquid chromatography-tandem mass spectrometry; GSH, glutathione; M1, debenzylated lapatinib; MRM, multiple reaction monitoring; UHPLC, ultra-high-performance liquid chromatography; XO, xanthine oxidase. 
HepaRG cells and was correlated with increased reactive metabolite generation (Hardy et al., 2014). Moreover, debenzylated lapatinib was more cytotoxic to HepaRG cells compared with the parent drug (Hardy et al., 2014). In the clinical setting, the risk of lapatinib-induced hepatotoxicity was increased in breast cancer patients taking dexamethasone and lapatinib compared with patients treated with lapatinib alone (Teo et al., 2012). These observations suggest at least a partial role of lapatinib metabolites in mediating hepatotoxicity.

We have previously shown that both CYP3A4 and CYP3A5 contribute to lapatinib bioactivation (Towles et al., 2016); however, the impact of $C Y P 3 A 5$ polymorphism on lapatinib metabolism has not been fully established (Chan et al., 2014; Ho et al., 2015). CYP3A5 shares $84 \%$ sequence identity with CYP3A4 (Aoyama et al., 1989), and the enzymes share overlapping substrates (Wrighton and Stevens, 1992; Huang et al., 2004). Whereas CYP3A4 is abundantly expressed in human liver and intestine, CYP3A5 is highly polymorphic (Hustert et al., 2001; Kuehl et al., 2001; Lamba et al., 2002; Lin et al., 2002). The presence of the $C Y P 3 A 5 * 1$ wild-type allele leads to expression of high levels of functional CYP3A5 protein, whereas the most common CYP3A5 variant allele $* 3$ results in low to undetectable levels of CYP3A5 owing to improper mRNA splicing (Kuehl et al., 2001). The CYP3A5*3/*3 genotype is most frequent among individuals of European descent (70\%-90\%); 30\%-40\% of Asians and 50\%-70\% of people of African descent carry at least one $C Y P 3 A 5 * 1$ allele (CYP3A5 expressers) (Hustert et al., 2001; Kuehl et al., 2001; Lamba et al., 2002). In CYP3A5 expressers, CYP3A5 may contribute significantly to overall CYP3A content and catalytic activity (Kuehl et al., 2001; Huang et al., 2004). An increasing number of examples indicate that CYP3A5 polymorphism can impact the metabolism and pharmacokinetics of CYP3A substrates, including tacrolimus (Hesselink et al., 2003; Birdwell et al., 2015), alfentanil (Klees et al., 2005), vincristine (Dennison et al., 2007), and maraviroc (Lu et al., 2012, 2014).

Recent tools have been developed to differentiate between CYP3A4 and CYP3A5 contributions to drug metabolism. CYP3cide and SR-9186 are CYP3A4-selective chemical inhibitors (Li et al., 2012; Walsky et al., 2012). The difference between inhibition by CYP3cide (CYP3A4selective inactivator) and ketoconazole (CYP3A pan inhibitor) has been used as an approach to estimate CYP3A5 contributions to metabolism of multiple CYP3A substrates (Tseng et al., 2014, 2018; Towles et al., 2016; Zientek et al., 2016). Further, $N$-oxidation of T- 5 was identified as a selective marker reaction to measure CYP3A5 activity (Li et al., 2014). This marker reaction can now be used to selectively evaluate the CYP3A5 genotype/phenotype relationship with respect to enzyme expression and activity.

The goal of the present study was to determine the effect of CYP3A5 genotype and CYP3A activity on the metabolic activation of lapatinib in genotyped human liver tissues. We hypothesized that CYP3A5 polymorphism would have a significant impact on lapatinib $O$-debenzylation and reactive metabolite formation. Studies were done to 1) examine lapatinib metabolism in $C Y P 3 A 5$-genotyped human liver microsomes and cryopreserved human hepatocytes, 2) assess the correlation between metabolite formation and CYP3A and CYP3A5-selective activity, and 3) estimate the relative contributions of CYP3A4 and CYP3A5 to lapatinib $O$-debenzylation.

\section{Materials and Methods}

\section{Chemicals and Reagents}

Lapatinib (free base; L-4899) was purchased from LC Laboratories (Woburn, MA). M1 was chemically synthesized according to the methods described previously (Teng et al., 2010). Deuterium-labeled $O$-debenzylated lapatinib $\left(\left[{ }^{2} \mathrm{H}_{4}\right]\right.$ $O$-debenzylated lapatinib, $\mathrm{d}_{4}$-Lap-OH, C-10309) was chemically synthesized and provided by CoNCERT Pharmaceuticals (Lexington, MA), as described previously (Towles et al., 2016). Lapatinib stock solutions were prepared in dimethylsulfoxide (DMSO), and working solutions were prepared in 1:9 DMSO/acetonitrile (v/v). Reduced glutathione (GSH), allopurinol, hydralazine hydrochloride, and $O^{6}$-benzylguanine were purchased from Sigma-Aldrich (St. Louis,MO). Midazolam, 1'-hydroxymidazolam, and $\mathrm{d}_{4}-1^{\prime}$-hydroxymidazolam were purchased from Cerilliant Corporation (Round Rock, TX). T-5 (T-1032, [methyl 2-(4-aminophenyl)-1-oxo-7-(pyridin-2-ylmethoxy)-4- (3,4,5-trimethoxyphenyl)-1,2-dihydroisoquinoline-3-carboxylate]) ( $\mathrm{Li}$ et al., 2014), and T-5 $N$-oxide standards were gifts from Michael Cameron (The Scripps Research Institute, Jupiter, FL). Stock solutions were prepared in DMSO, diluted in 1:9 DMSO/acetonitrile (v/v) working solutions, and stored at $-20^{\circ} \mathrm{C}$.

An NADPH-regenerating system, consisting of solution A (26 mM NADP+, $66 \mathrm{mM}$ glucose 6-phosphate, $66 \mathrm{mM} \mathrm{MgCl} 2$ in water) and solution $\mathrm{B}(40 \mathrm{U} / \mathrm{ml}$ glucose 6-phosphate dehydrogenase in $5 \mathrm{mM}$ sodium citrate), was purchased from Corning Life Sciences (Corning, NY). OptiThaw media kit (Product no. K8000) was purchased from Sekisu XenoTech, LLC (Kansas City, KS). InVitroGRO Krebs-Henseleit buffer (KHB) medium (product no. Z99074) was purchased from BioreclamationIVT (now BioIVT, New York, NY).

\section{Human Liver Subcellular Fractions and Cryopreserved Hepatocytes}

Human Liver Microsomes. Pooled human liver microsomes from 150 donors, mixed gender (lot number 38291; Corning) were purchased from Corning Life Sciences. Single-donor human liver microsomal samples from 12 donors genotyped for CYP3A5 were purchased from Corning Life Sciences and XenoTech, LLC. Donors included eight males (M) and four females (F), aged 26-66 years. CYP3A5 genotype reported by the company for each donor was as follows: $C Y P 3 A 5 * 1 / * 1$ donors were $\mathrm{HH} 860(\mathrm{~F}), \mathrm{HH} 867(\mathrm{M}), \mathrm{HH} 785(\mathrm{M})$, 710272(F); CYP3A5*1/*3 donors were HH757(M), HH868(M), 710232(F); CYP3A5*3/*3 donors were HH189(F), HH507(M), 710252(M), 710253(M), and 710237(M).

Human Liver S9 Fraction. Human liver S9 fraction pooled from 10 donors (mixed gender) was prepared according to procedures described previously (Towles et al., 2016). Commercially available human liver S9 fraction pooled from 20 donors (mixed gender) was purchased from XenoTech (catalog no. H0606.S9(AX), lot no. 1710129).

Cryopreserved Human Hepatocytes. Cryopreserved human hepatocytes pooled from five donors (mixed gender) were purchased from BioIVT. CYP3A5genotyped cryopreserved human hepatocytes pooled from three donors (mixed gender) were purchased from XenoTech. Lot HPCH.3A5.HA with genotype CYP $3 A 5^{*} 1 / * 1$ was classified as "high activity" (donors 979, 1019, 1057; two M, one F); lot HPCH.3A5.MA with genotype $C Y P 3 A 5^{*} 1 / * 3$ was classified as "medium activity" (donors 1173, 1186, 1203; one M, two F); and lot HPCH.3A5.NA. with genotype CYP3A5*3/*3 was classified as "no activity" (donors 1196, 1207, 1211; one M, two F). CYP3A activity in each pooled lot was measured by XenoTech using testosterone $6 \beta$-hydroxylation and midazolam $1^{\prime}$-hydroxylation as marker reactions.

Single-donor cryopreserved human hepatocytes from 15 donors genotyped for CYP3A5 were purchased from BioIVT. Hepatocyte donors included eight $\mathrm{M}$ and seven F, aged 39-68 years. CYP3A5*1/*1 donors were RSA(M), RQM(F); CYP $3 A 5^{*} 1 / * 3$ donors were GTD(M), DGW(M), ZUJ(M), KCM(F), OWY(F); CYP3A5*3/*3 donors were YUA(M), ORM(M), EFF(M), BTA(M), OTH(F), $\mathrm{CBD}(\mathrm{F}), \mathrm{XUA}(\mathrm{F})$, and JYS(F).

\section{Measurement of CYP3A and CYP3A5-Selective Activity in Human Liver Microsomes}

Measurement of CYP3A and CYP3A5-Selective Activity. Midazolam 1'hydroxylation was used as a marker of CYP3A activity, as described previously (Walsky and Obach, 2004). Briefly, midazolam $(2.5 \mu \mathrm{M})$ was incubated with single-donor human liver microsomal fractions $(0.03 \mathrm{mg}$ protein $/ \mathrm{ml})$ supplemented with NADPH-regenerating system. Reactions were initiated with the addition of NADPH solution A; the final incubation volume was $0.2 \mathrm{ml}$. Control incubations were without NADPH-regenerating system. Incubations were carried out for 4 minutes at $37^{\circ} \mathrm{C}$ in a shaking water bath. Reactions were quenched by the

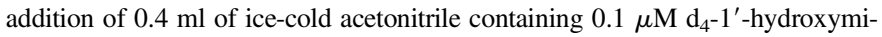
dazolam (internal standard), mixed with a vortex device for 10 seconds, and centrifuged for 20 minutes at $3700 \mathrm{~g}\left(4^{\circ} \mathrm{C}\right)$. The clear supernatant was transferred 
into liquid chromatography-mass spectrometry (LC-MS) vials, and a $10 \mu$ l-aliquot was subjected to LC-MS/MS analysis. Levels of 1 '-hydroxymidazolam were measured by LC-MS/MS using a standard curve $(1,5,10,25,50,100,250,500$, $1000 \mathrm{nM} \mathrm{1'-hydroxymidazolam)} \mathrm{(Walsky} \mathrm{and} \mathrm{Obach,} \mathrm{2004).}$

$\mathrm{T}-5 \mathrm{~N}$-oxidation was used as a selective marker reaction for CYP3A5 activity, as described by Li et al. (2014). Briefly, T-5 $(5 \mu \mathrm{M})$ was incubated with singledonor human liver microsomal fractions $(0.1 \mathrm{mg}$ protein $/ \mathrm{ml})$ supplemented with NADPH-generating system. Reactions were initiated with the addition of NADPH solution A; the final incubation volume was $0.2 \mathrm{ml}$. Control incubations were without NADPH-regenerating system. The final organic solvent concentration was $0.1 \% \mathrm{DMSO} / 0.9 \%$ acetonitrile $(\mathrm{v} / \mathrm{v})$. Incubations were carried out for 15 minutes at $37^{\circ} \mathrm{C}$ in a shaking water bath. Reactions were quenched by the addition of $0.4 \mathrm{ml}$ of ice-cold acetonitrile containing $0.1 \mu \mathrm{M} \mathrm{d}_{4}-1^{\prime}$-hydroxymidazolam (internal standard) and prepared for LC-MS analysis as described herein. $\mathrm{T}-5 \mathrm{~N}$-oxide was quantified by LC-MS/MS analysis using a standard curve $(5,10$, 25, 50, 100, 250, 500, $2500 \mathrm{nM}$ T-5 $N$-oxide) (Li et al., 2014). Standards were prepared in a matrix like that used in the experimental samples. Working solutions of standards were diluted into $100 \mathrm{mM}$ potassium phosphate and $0.1 \mathrm{mg}$ protein/ $\mathrm{ml}$ of pooled human liver microsomes without NADPH-regenerating system. For measurement of midazolam 1 '-hydroxylation and T-5 $N$-oxidation, three independent experiments were performed in triplicate each.

\section{Lapatinib Metabolism in Genotyped Human Liver Microsomes}

Lapatinib $(5 \mu \mathrm{M})$ was incubated with single-donor human liver microsomal fractions $(0.1 \mathrm{mg}$ protein/ml) supplemented with $5 \mathrm{mM} \mathrm{GSH}$ and an NADPHregenerating system. Reactions were initiated with the addition of NADPH solution A; the final incubation volume was $0.2 \mathrm{ml}$. Control incubations were without NADPH-regenerating system. Incubations were carried out for 20 minutes at $37^{\circ} \mathrm{C}$ in a shaking water bath. Reactions were quenched by the addition of $0.4 \mathrm{ml}$ of ice-cold acetonitrile containing $100 \mathrm{ng} / \mathrm{ml} \mathrm{d}_{4}$-debenzylated lapatinib (internal standard), mixed with a vortex device for 10 seconds, and centrifuged for 20 minutes at $3700 \mathrm{~g}\left(4^{\circ} \mathrm{C}\right)$. The clear supernatant $(\sim 0.5 \mathrm{ml})$ was transferred to a separate vial, and the solvent was evaporated under $\mathrm{N}_{2}$ gas using a TurboVap (Biotage, Charlotte, NC) to concentrate the samples. The dried sample residue was redissolved with $0.1 \mathrm{ml}$ of 80:20 LC-MS-grade water/acetonitrile (v/v), mixed with a vortex device for 10 seconds, and centrifuged for 5 minutes at $20,000 \mathrm{~g}$ (room temperature). The supernatant $(\sim 0.1 \mathrm{ml})$ was transferred to an LC-MS vial, and a 15- $\mu 1$ aliquot was subjected to LC-MS/MS analysis for measurement of relative levels of M1 and quinone imine-GSH conjugates (Hardy et al., 2014; Towles et al., 2016).

\section{Effect of CYP3A Inhibitors on Lapatinib Metabolism in Genotyped Human Liver Microsomes}

Lapatinib $(5 \mu \mathrm{M})$ was incubated with pooled and individual genotyped human liver microsomes $(0.1 \mathrm{mg} / \mathrm{ml})$ in $100 \mathrm{mM}$ potassium phosphate buffer $(\mathrm{pH} 7.4)$ supplemented with $5 \mathrm{mM} \mathrm{GSH}$ and NADPH-regenerating system for 20 minutes in the presence and absence of CYP3A4-selective inhibitor CYP3cide $(2 \mu \mathrm{M})$ and pan-CYP3A inhibitor ketoconazole $(1 \mu \mathrm{M})$ to determine the relative CYP3A5 contributions to lapatinib metabolite formation (Walsky et al., 2012). CYP3cide was used without preincubation, as described by Tseng et al. (2014). Vehicle control incubations included solvent (1:9 DMSO: acetonitrile, v/v) without inhibitor. Reactions were initiated by the addition of NADPH solution A. Samples were processed as described already herein. Lapatinib metabolites were analyzed by LC-MS/MS, and metabolite formation was compared with vehicle control incubations without inhibitors. Pooled human liver microsomes from 150 donors, mixed gender (Corning Life Sciences), were used to assess metabolite formation in an "average" population. Human liver microsomes from seven individual genotyped donors were used in these experiments as follows: $C Y P 3 A 5 * 1 / * 1$, $n=4$ : HH860(F), HH867(M), HH785(M), 710272(F); CYP3A5*3/*3, $n=3$ : 710252(M), 719253(M), 710237(M). Two independent experiments were performed in triplicate each to assess reproducibility.

Formation of lapatinib M1 (debenzylated lapatinib) was quantified by LC-MS/ MS analysis using a standard curve of chemically synthesized M1. Stock solutions of lapatinib M1 were prepared in DMSO. Working solutions were prepared in a similar matrix as the experimental samples. For quantitation from microsomal incubations, M1 standards were diluted 1:100 into $100 \mathrm{mM}$ potassium phosphate, $0.1 \mathrm{mg}$ protein/ml of pooled human liver microsomes without NADPH-regenerating system. Final standard concentrations of M1 were $0.001,0.0025,0.005,0.01$, $0.025,0.05,0.1,0.25,0.5,1 \mu \mathrm{g} / \mathrm{ml}$. M1 standards were prepared in duplicate and analyzed by LC-MS/MS analysis with the experimental samples.

\section{Lapatinib Metabolism in Genotyped Human Hepatocytes}

Incubations with cryopreserved human hepatocytes were carried out according to the suppliers' protocols (BioIVT and Xenotech) with slight modifications. Cell viability was determined by the trypan blue exclusion method.

Lapatinib $(10 \mu \mathrm{M})$ was incubated with pooled and single-donor cryopreserved human hepatocytes in suspension. Cells were seeded at a density of $0.5 \times 10^{6}$ cells $/ \mathrm{ml}$ in KHB in a 24 -well collagen coated-plated. The final incubation volume was $0.5 \mathrm{ml}$, and the final organic solvent concentration was $1 \%$ (1:9 DMSO/ acetonitrile, $\mathrm{v} / \mathrm{v})$. Incubations with pooled-donor hepatocytes were carried out for 2 hours, and incubations with single-donor CYP3A5-genotyped hepatocytes were carried out for 2.2 hours in a temperature-controlled plate shaker at $37^{\circ} \mathrm{C}$. To distinguish the CYP3A4 and CYP3A5 contributions to lapatinib metabolism, single-donor hepatocytes were coincubated with the CYP3A inhibitor ketoconazole $(1 \mu \mathrm{M})$ or the CYP3A4-selective inactivator CYP3cide $(2 \mu \mathrm{M})$ (Walsky et al., 2012; Tseng et al., 2014). After the incubation period, sample plates were placed on ice, and an equal volume $(0.5 \mathrm{ml})$ of ice-cold acetonitrile containing $100 \mathrm{ng} / \mathrm{ml} \mathrm{d}_{4}$-debenzylated lapatinib (internal standard) was added to precipitate the protein. The cell media mixture was transferred to a clean microcentrifuge tube and centrifuged for 20 minutes at $3700 \mathrm{~g}\left(4^{\circ} \mathrm{C}\right)$. The clear supernatant $(\sim 0.8 \mathrm{ml})$ was transferred to a separate vial, and the solvent was evaporated under $\mathrm{N}_{2}$ gas using a TurboVap system to concentrate the samples. Each dried sample residue was redissolved with $0.2 \mathrm{ml}$ of 80:20 LC-MS-grade water/acetonitrile (v/v), mixed with a vortex device for 10 seconds, and centrifuged for 5 minutes at $20,000 \mathrm{~g}$ (room temperature). The supernatant $(\sim 0.2 \mathrm{ml})$ was transferred to a clean LC-MS vial, and a 15- $\mu$ l aliquot was subjected to LC-MS/MS analysis for measurement of relative levels of lapatinib metabolites (Hardy et al., 2014). For quantitation of lapatinib M1 from hepatocyte incubations, M1 standard stock solutions were diluted 1:100 into KHB without cells. Final standard concentrations of M1 were $0.001,0.0025,0.005,0.01,0.025,0.05,0.1,0.25,0.5$, and $1 \mu \mathrm{g} / \mathrm{ml}$. As noted previously, M1 standards were prepared in duplicate and were analyzed by LC-MS/MS with the experimental samples.

CYP3A and CYP3A5-selective activities were measured in hepatocytes using midazolam and T-5 as probe substrates, respectively. Midazolam $(2.5 \mu \mathrm{M})$ and T-5 $(5 \mu \mathrm{M})$ were incubated separately with pooled and single-donor cryopreserved human hepatocytes in suspension at a cell density of $0.5 \times 10^{6}$ cells $/ \mathrm{ml}$ in $\mathrm{KHB}$ in a 24-well collagen coated-plate. The final incubation volume was $0.5 \mathrm{ml}$, and the final organic solvent concentration was $1 \%$ (1:9 DMSO/acetonitrile, v/v). Incubations were carried out for 30 minutes, in a temperature-controlled plate shaker at $37^{\circ} \mathrm{C}$. After the incubation period, sample plates were placed on ice, and an equal volume $(0.5 \mathrm{ml})$ of ice-cold acetonitrile containing $0.1 \mu \mathrm{M} \mathrm{d}_{4}-1^{\prime}$ hydroxymidazolam (internal standard) was added. The cell media mixture was transferred to a clean microcentrifuge tube as described already and centrifuged for 20 minutes at $3700 \mathrm{~g}\left(4^{\circ} \mathrm{C}\right)$. The supernatant was transferred to an LC-MS vial, and samples were subjected to LC-MS/MS analysis for measurement of 1'hydroxymidazolam and T-5 $\mathrm{N}$-oxide. Incubations with single-donor cryopreserved hepatocytes were performed as a single experiment on multiple days (three to four donors per day, for 4 days) in at least three replicates per donor. All samples were analyzed by LC-MS on the same day. Formation of 1'-hydroxymidazolam and T-5 $\mathrm{N}$-oxide was quantified by LC-MS/MS analysis using standard curves for each compound; levels are reported as picomoles per minute per million live cells $(\mathrm{Li}$ et al., 2014). A standard curve of $1^{\prime}$-hydroxymidazolam $(1,5,10,25,50,100,250$, $500,1000 \mathrm{nM}$ ) was used for quantitation of 1 '-hydroxymidazolam (Walsky and Obach, 2004), and a standard curve of T-5 $N$-oxide $(5,10,25,50,100,250,500$, $2500 \mathrm{nM}$ ) was used for quantitation of T-5 $\mathrm{N}$-oxide ( $\mathrm{Li}$ et al., 2014). $\mathrm{D}_{4}-\mathrm{1}^{\prime}$ hydroxymidazolam $(0.1 \mu \mathrm{M})$ used as the internal standard for both analytes. Standards were prepared in a similar matrix as the experimental samples, but without cells; standards were diluted into KHB to the desired concentration. The standards were analyzed with experimental samples from incubations with cryopreserved human hepatocytes for metabolite quantitation on the same day.

\section{Lapatinib Metabolism in Pooled Human Liver S9 Fraction}

Dick (2018) recently proposed that aldehyde oxidase (AO) mediates hydroxylation of lapatinib to AO-M1 and hydroxylation of debenzylated lapatinib 
to M3. To examine lapatinib metabolism by P450 and AO, lapatinib and debenzylated lapatinib $(10 \mu \mathrm{M})$ were incubated with 10-donor pooled human liver S9 fraction $(2.5 \mathrm{mg}$ protein $/ \mathrm{ml})$ in $100 \mathrm{mM}$ potassium phosphate $(\mathrm{pH} 7.4)$ supplemented with $5 \mathrm{mM} \mathrm{GSH}$ in the presence and absence of NADPHgenerating system. The final incubation volume was $0.2 \mathrm{ml}$. Aliquots $(0.08 \mathrm{ml})$ of the reaction mixture were removed at 60 and 120 minutes and combined with twice the volume $(0.16 \mathrm{ml})$ of ice-cold acetonitrile containing $100 \mathrm{ng} / \mathrm{ml}$ $\mathrm{d}_{4}$-debenzylated lapatinib (internal standard). The resulting samples were mixed with a vortex device for 10 seconds and centrifuged for 20 minutes at 20,000g $\left(4^{\circ} \mathrm{C}\right)$. The clear supernatant $(\sim 0.2 \mathrm{ml})$ was transferred to a separate vial, dried under $\mathrm{N}_{2}$ gas, and redissolved with $0.1 \mathrm{ml}$ of 80:20 LC-MS-grade water/ acetonitrile (v/v), as described already. The resulting sample was subjected to LCMS/MS analysis for measurement of relative levels of lapatinib metabolites, including debenzylated lapatinib (M1), AO-M1 (Dick, 2018), M3 (Castellino et al., 2012), and quinone imine-GSH conjugates (Hardy et al., 2014; Towles et al., 2016)

\section{Lapatinib and Debenzylated Lapatinib Metabolism in Pooled Human Liver S9 with AO and XO Inhibitors}

To confirm the role of AO in the formation of lapatinib AO-M1 and M3 and to evaluate a potential role of the related cytosolic enzyme xanthine oxidase (XO) in the formation of these metabolites, each substrate (lapatinib, $5 \mu \mathrm{M}$, debenzylated lapatinib, $2.5 \mu \mathrm{M})$ was incubated at $37^{\circ} \mathrm{C}$ in a potassium phosphate $(100 \mathrm{mM}, \mathrm{pH}$ 7.4) buffered mixture containing 20-donor pooled human liver $\mathrm{S} 9$ fraction $(2.5 \mathrm{mg}$ protein $/ \mathrm{ml}$ ) in the presence and absence of either the AO inhibitor hydralazine $(25 \mu \mathrm{M})$ or the $\mathrm{XO}$ inhibitor allopurinol $(100 \mu \mathrm{M})$. The final incubation volume was $0.2 \mathrm{ml}$. Mixtures were preincubated with hydralazine (or vehicle) for 30 minutes at $37^{\circ} \mathrm{C}$, and then allopurinol (or vehicle) was added to the appropriate vials, immediately followed by the addition of substrate to initiate the reaction. After incubation for 60 minutes, the reaction was terminated with the addition of $0.4 \mathrm{ml}$ of ice-cold acetonitrile containing $100 \mathrm{ng} / \mathrm{ml} \mathrm{d}_{4}$-debenzylated lapatinib (internal standard). The resulting samples were centrifuged for 20 minutes at $3740 \mathrm{~g}\left(4^{\circ} \mathrm{C}\right)$. The clear supernatant $(0.2 \mathrm{ml})$ was transferred to a separate vial for LC-MS/MS analysis of AO-M1 or M3 formation. Two independent experiments were performed in triplicate to verify reproducibility, and an incubation with heat inactivated $\mathrm{S} 9$ (pre-heated at $\sim 100^{\circ} \mathrm{C}$ for 10 minutes) was included to serve as a negative control. No positive control for $\mathrm{XO}$ activity was included; however, the S9 fractions were previously characterized for both $\mathrm{AO}$ and $\mathrm{XO}$ activity by the vendor (XenoTech), confirming active AO and XO. Some human liver S9 and/or cytosolic fractions have been reported to lack XO activity owing to the use of allopurinol during liver tissue processing (Barr et al., 2014); however, according to the vendor, human liver $\mathrm{S} 9$ fractions used in these studies were processed in the absence of allopurinol. Positive control incubations with the known AO substrate $O^{6}$-benzylguanine $(5 \mu \mathrm{M})$ were included to confirm AO activity (Roy et al., 1995), which was confirmed by monitoring 8 -oxidation of $O^{6}$-benzylguanine (8-oxo-benzylguanine formation) in positive control incubations (data not shown).

\section{LC-MS/MS Analysis of Metabolites}

Metabolites of lapatinib and probe substrates were measured by LC-MS/MS analysis. The LC-MS/MS system was similar to that described by Amaya et al. (2018). Briefly, a Shimadzu Prominence XR ultra-high-performance liquid chromatography (UHPLC) system was equipped with two Shimadzu LC-20ADXR pumps (Shimadzu Corp., Kyoto, Japan), SIL-20ACXR autosampler, and a CTO$20 \mathrm{~A}$ column oven heated to $32^{\circ} \mathrm{C}$. The UHPLC system was coupled to a Shimadzu MS/MS 8030 triple quadrupole mass spectrometer (Amaya et al., 2018). A Phenomenex Kinetex C18 octadecylsilane column $(2.6 \mathrm{~mm}, 50 \times 2.1 \mu \mathrm{m}, 100 \AA)$ was used to achieve analyte separation. The mobile-phase flow rate was $0.3 \mathrm{ml} / \mathrm{min}$. Mobile phase A was $0.1 \%$ formic acid in LC-MS-grade water, and mobile phase B was $0.1 \%$ formic acid in LC-MS-grade acetonitrile (v/v). Two UHPLC gradient programs were used for analysis of lapatinib metabolites and marker reactions. $\mathrm{LC}$ gradient program 1 was as follows: $0-1.0$ minute $(5 \% \mathrm{~B})$, linear gradient from 1.0 to 2.0 minutes (5\%-95\% B), 2.0-3.5 minutes (95\% B), 3.5-3.6 minutes $(95 \%-5 \%$ B), 3.6-5 minutes (5\% B) (all v/v). LC gradient program 2, which was used for quantitation of lapatinib M1, was as follows: linear gradient from 0 to 2.00 minutes $(10 \%-95 \%$ B), $2.00-2.50$ minutes $(95 \%$ B), $2.50-2.51$ minutes $(95 \%-10 \%$ B), 2.51-4.00 minutes (10\% B) (all v/v). A sample injection volume of $10-15 \mu l$ was injected via an autosampler onto an equilibrated UHPLC column, and the eluent was introduced directly into the mass spectrometer via electrospray ionization in positive ion mode. MS spectral data were acquired and analyzed using Shimadzu LabSolutions software (Amaya et al., 2018).

Lapatinib, probe substrates, and their respective metabolites were detected and quantified by LC-MS/MS using multiple reaction monitoring (MRM). The MRM precursor-to-product ion transitions for lapatinib and lapatinib metabolites were $\mathrm{m} / \mathrm{z} 581.6 \rightarrow 365$ (lapatinib), $\mathrm{m} / \mathrm{z}, 473 \rightarrow 350$ (debenzylated lapatinib, M1), $\mathrm{m} / z$ $778 \rightarrow 655$ (quinone imine-GSH conjugate), as described previously (Towles et al., 2016). The MRM transitions for the putative AO-mediated metabolites of lapatinib and debenzylated lapatinib were $m / z 597 \rightarrow 474$ (AO-M1), $m / z 489 \rightarrow$ 366 (M3) (Castellino et al., 2012; Dick, 2018). Formation of 1'hydroxymidazolam (measure of CYP3A activity) was detected using the MRM transition $m / z 342 \rightarrow 324$, and $\mathrm{d}_{4}{ }^{-1}{ }^{\prime}$-hydroxymidazolam $(\mathrm{m} / \mathrm{z}, 346 \rightarrow 328)$ was used as the internal standard according to the methods described by Walsky and Obach (2004). The MRM transitions for T-5 and T-5 metabolites were $m / z, 568.2$ $\rightarrow 476.2(\mathrm{~T}-5), \mathrm{m} / \mathrm{z} 584.2 \rightarrow 476.2(\mathrm{~T}-5 \mathrm{~N}$-oxide), $\mathrm{m} / \mathrm{z} 477.2 \rightarrow 445.2$ ( $O$-dealkylated T-5), according to the methods described previously ( $\mathrm{Li}$ et al., 2014).

Formation of 8-oxo-benzylguanine (from $O^{6}$-benzylguanine) was determined by using LC-MS/MS analysis with an electrospray ionization enabled Sciex QTRAP 6500 triple quadrupole instrument (Sciex, Foster City, CA) that was coupled to Shimadzu LC-20ADXR pumps (Shimadzu Corp.) and a CTC PAL autosampler (Leap Technologies, Carrboro, NC). Analytes were separated by gradient elution after a $10-\mu 1$ injection onto a Phenomenex Kinetex EVO C18 $100 \AA$ column $(1.7 \mu \mathrm{m}, 50 \times 2.1 \mathrm{~mm})$ operating at $40^{\circ} \mathrm{C}$. Mobile phase A was $0.1 \%$ formic acid in LC-MS grade water and mobile phase B was $0.1 \%$ formic acid in LC-MS grade acetonitrile (v/v). The flow rate was $0.5 \mathrm{ml} / \mathrm{min}$, and the LC gradient was as follows: $0-0.2$ minutes $(5 \% \mathrm{~B})$, linear gradient from 0.2 to 1.2 minutes $(5 \%-95 \% \mathrm{~B}), 1.2-1.4$ minutes $(95 \% \mathrm{~B}), 1.4-1.5$ minutes $(95 \%-5 \% \mathrm{~B}), 1.5-2.0$ minutes $(5 \% \mathrm{~B})$. The total run time was 2.0 minutes. Mass spectral analyses were performed using MRM, with transitions and voltages specific for each analyte, using a turbo ion spray source (source temperature $\left.650^{\circ} \mathrm{C}\right)$ in positive ionization mode $(5.50 \mathrm{kV}$ spray voltage). MRM transitions were the following: $O^{6}$-benzylguanine $(\mathrm{m} / z, 242 \rightarrow 199)$, 8-oxo-benzylguanine $(\mathrm{m} / \mathrm{z}, 258 \rightarrow 91)$ (Barr et al., 2014), and the internal standard, carbamazepine $(\mathrm{m} / \mathrm{z}$ $237 \rightarrow 194)$. Data were analyzed using Sciex Analyst 1.7.0 software.

\section{Statistical Analysis}

All statistical analyses were performed using GraphPad Prism 7 software (GraphPad, San Diego, CA). Formation of lapatinib M1 and quinone imine-GSH conjugates in single-donor human liver microsomes and hepatocytes was analyzed for correlation with midazolam $1^{\prime}$-hydroxylation (CYP3A activity) and T-5 $\mathrm{N}$-oxidation (CYP3A5-selective activity) using linear regression analysis and Pearson $r$ correlation. Lapatinib metabolism, midazolam 1'-hydroxylation, and T-5 $N$-oxidation were compared across CYP3A5 genotypes $(* 1 / * 1, * 1 / * 3$, and *3/*3) by one-way ANOVA. Comparison of lapatinib M1 formation and midazolam 1'-hydroxylation by sex (male vs. female) was performed by unpaired student $t$ test. Outlier analysis was conducted using Grubb's outlier method. Experiments were performed in triplicate unless otherwise stated. Statistical significance was determined at $P<0.05$.

\section{Results}

Measurement of CYP3A and CYP3A5 Activity in Genotyped Human Liver Microsomes. CYP3A and CYP3A5-selective activity were measured in $C Y P 3 A 5$-genotyped human liver microsomes to assess the genotype-phenotype relationship. Individual human liver microsomal samples included $C Y P 3 A 5 * 3 / * 3$ donors, $n=5$; $C Y P 3 A 5 * 1 / * 3$ donors, $n=3$; and $C Y P 3 A 5 * 1 / * 1$ donors, $n=4$. CYP3A activity, as measured by midazolam 1 '-hydroxylation, varied widely between liver microsomes from individual donors $(23-1754 \mathrm{pmol} / \mathrm{min}$ per milligram protein); however, midazolam 1'-hydroxylation did not significantly differ compared by $C Y P 3 A 5$ genotype among the 12 donors analyzed in this study (one-way ANOVA, $P=0.2775$ ) (Fig. 1A).

T-5 $N$-oxidation has been reported as a selective marker reaction for CYP3A5 activity (Li et al., 2014). In the present study, T-5 $\mathrm{N}$-oxide 
A

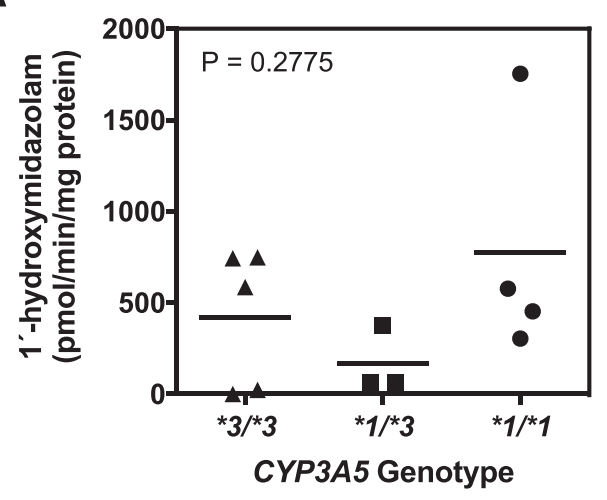

B

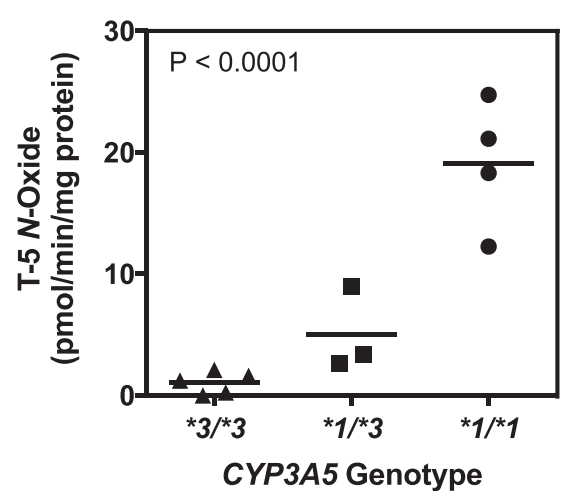

Fig. 1. Measurement of CYP3A activity by midazolam $1^{\prime}$-hydroxylation and CYP3A5-selective activity by $\mathrm{T}-5 \mathrm{~N}$-oxidation in genotyped human liver microsomes. (A) Midazolam $(2.5 \mu \mathrm{M})$ was incubated with single-donor human liver microsomes $(0.03 \mathrm{mg}$ protein $/ \mathrm{ml})$ supplemented with NADPH-generating system for 4 minutes. (B) T-5 $(5 \mu \mathrm{M})$ was incubated with single-donor human liver microsomes $(0.1 \mathrm{mg}$ protein $/ \mathrm{ml})$ supplemented with NADPH-generating system for 15 minutes. Formation of $1^{\prime}$-hydroxymidazolam and T-5 $N$-oxide was measured by LC-MS/MS analysis. Each point is the mean of three experiments, each performed in triplicate. $C Y P 3 A 5 * 3 / * 3$ donors, $n=5$; $C Y P 3 A 5 * 1 / * 3$ donors, $n=3$; $C Y P 3 A 5 * 1 / * 1$ donors, $n=4$. Metabolite formation was compared across $C Y P 3 A 5$ genotypes by one-way ANOVA using GraphPad Prism 7 software.

formation in human liver microsomes was significantly associated with CYP3A5 genotype in the following order: CYP3A5*3/*3<*1/*3< $* 1 / * 1$ (one-way ANOVA, $P<0.0001$ ) (Fig. 1B). The rates of T-5 $N$-oxidation in human liver microsomal samples were $0-2.1 \mathrm{pmol} / \mathrm{min}$ per milligram protein among $C Y P 3 A 5 * 3 / * 3$ donors $(n=5) ; 3.4-9.0$ $\mathrm{pmol} / \mathrm{min}$ per milligram protein in $C Y P 3 A 5^{*} 1 / * 3$ donors $(n=3)$; and $12-25 \mathrm{pmol} / \mathrm{min}$ per milligram protein in $C Y P 3 A 5^{*} 1 / * 1$ donors $(n=4)$. Moreover, the mean rates of T- $5 \mathrm{~N}$-oxide formation were 19 -fold greater in $C Y P 3 A 5 * 1 / * 1$ donors compared with $C Y P 3 A 5 * 3 / * 3$ donors (mean \pm S.D.): $19 \pm 5.3$ versus $1.0 \pm 0.9 \mathrm{pmol} / \mathrm{min}$ per milligram protein, respectively. These results confirm the positive relationship between CYP3A5 genotype and CYP3A5 enzyme activity in human liver microsomal fractions.

Lapatinib Bioactivation in Genotyped Human Liver Microsomes. Formation of debenzylated lapatinib (M1) and quinone imineGSH conjugates was examined in CYP3A5-genotyped human liver microsomes from 11 of the 12 donors analyzed. $(C Y P 3 A 5 * 1 / * 3$ donor HH757 was not included in this analysis owing to the limited amount of this sample available at the time of analysis). Relative levels of M1 (peak area ratio) trended toward greater formation in $C Y P 3 A 5 * 1 / * 1$ donors compared with $C Y P 3 A 5 * 3 / * 3$ donors, but the difference was not statistically significant (Fig. 2A). Relative levels of quinone imineGSH conjugates did not differ by $C Y P 3 A 5$ genotype in human liver microsomes (Fig. 2B).
M1 formation was significantly correlated with CYP3A activity, as measured by midazolam $1^{\prime}$-hydroxylation $\left(r^{2}=0.75, n=11\right.$, $P=0.0006)$, and CYP3A5-selective activity, as measured by T-5 $N$-oxidation $\left(r^{2}=0.51, n=11, P=0.0142\right)$ in human liver microsomes (Fig. 3, A and B). Formation of quinone imine-GSH conjugates was significantly correlated with midazolam 1 -hydroxylation $\left(r^{2}=0.91\right.$, $n=11, P<0.0001)$, but not T-5 $N$-oxidation $\left(r^{2}=0.32, n=11\right.$, $P=0.0681$ ) (Fig. 3, C and D). The relationship between lapatinib $O$-debenzylation and subsequent quinone imine formation was also evaluated. Formation of quinoneimine-GSH conjugates significantly correlated with the levels of M1 $\left(r^{2}=0.83, n=11, P<0.0001\right)$ (Fig. 3E). This finding is consistent with the fact that debenzylated lapatinib (M1) is a precursor to the reactive quinone imine (Teng et al., 2010). Collectively, these results demonstrate that lapatinib bioactivation via oxidative $O$-debenzylation and formation of the reactive quinone imine (trapped as a GSH conjugate) is strongly correlated with total microsomal CYP3A activity (midazolam 1'-hydroxylation).

Effect of CYP3A-Selective Inhibitors on Microsomal Lapatinib $\boldsymbol{O}$-Debenzylation. Recently developed CYP3A4-selective inhibitors have allowed for distinguishing between CYP3A4 and CYP3A5 contributions to drug metabolism in vitro (Walsky et al., 2012). We examined the relative contributions of CYP3A4 and CYP3A5 to lapatinib $O$-debenzylation in human liver microsomes using the CYP3A4-selective
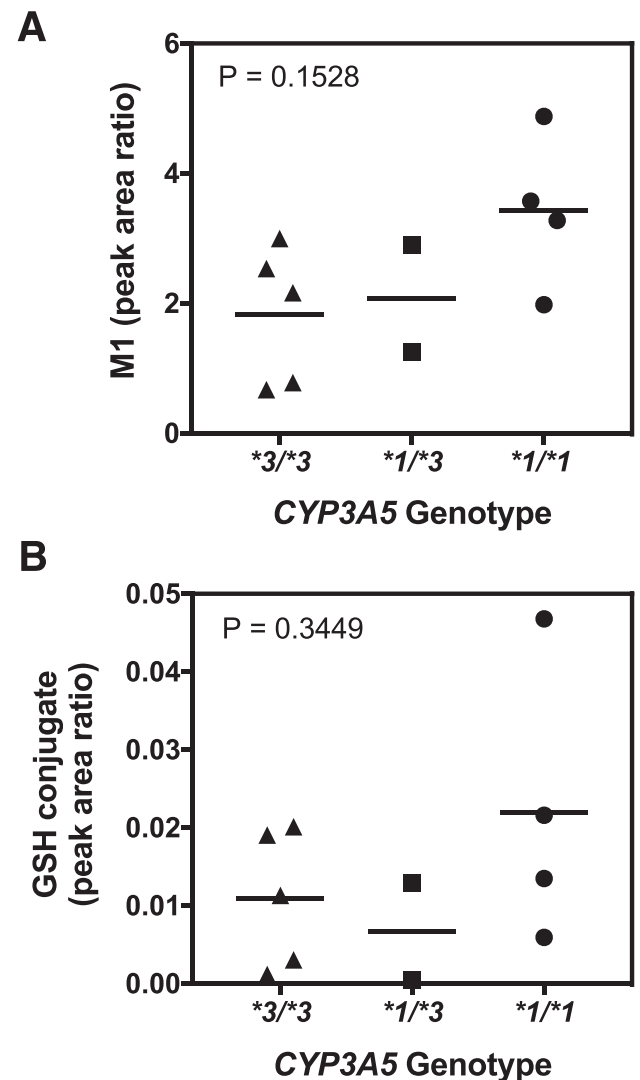

Fig. 2. Lapatinib $O$-debenzylation and formation of quinone imine-GSH conjugates in genotyped human liver microsomes. Lapatinib $(5 \mu \mathrm{M})$ was incubated with singledonor human liver microsomes $(0.1 \mathrm{mg}$ protein $/ \mathrm{ml})$ supplemented with an NADPHgenerating system for 20 minutes. Formation of debenzylated lapatinib, M1 (A) and quinone imine-GSH conjugates (B) was measured by LC-MS/MS analysis. Relative metabolite levels are reported as peak area ratio (metabolite peak area/internal standard peak area). Each point is the mean of two to three experiments, each performed in triplicate. $C Y P 3 A 5 * 3 / * 3$ donors, $n=5$; CYP $3 A 5 * 1 / * 3$ donors, $n=2$; $C Y P 3 A 5^{*} 1 / * 1$ donors, $n=4$. Metabolite formation was compared across $C Y P 3 A 5$ genotypes by one-way ANOVA using GraphPad Prism 7 software. 
A

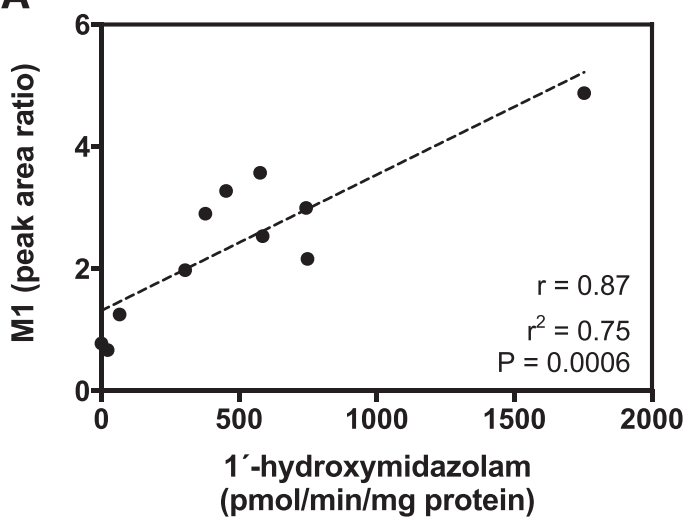

B

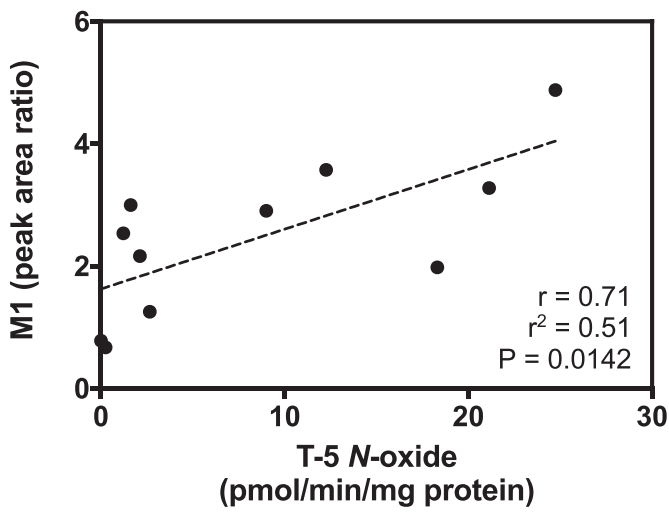

C

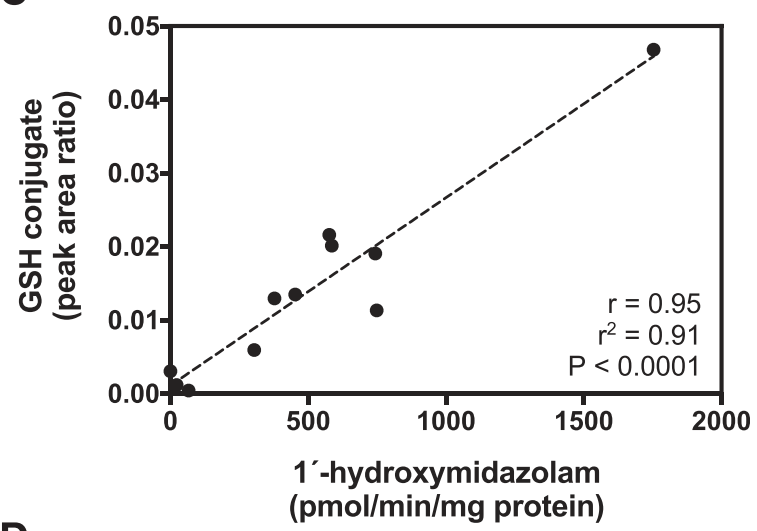

D

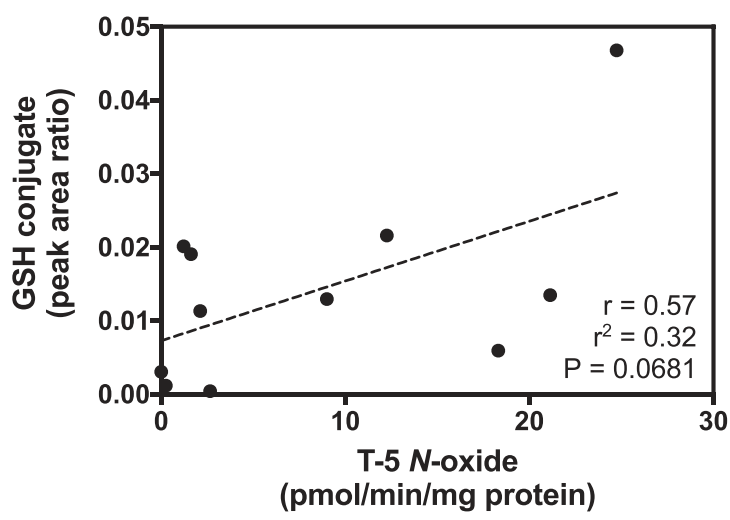

E

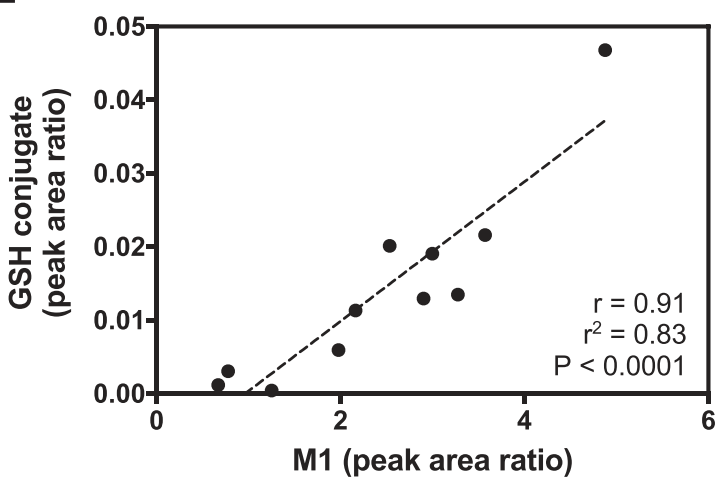

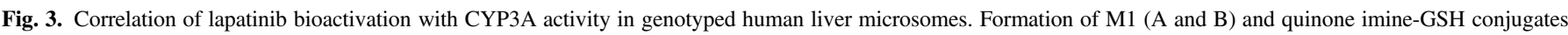

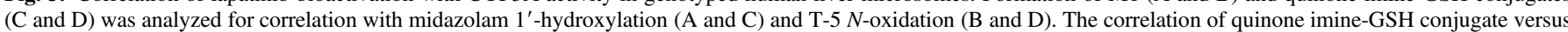

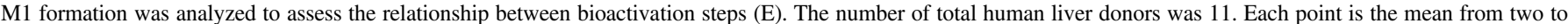
three experiments, each performed in triplicate. Linear regression analysis was performed to determine $r^{2}$ and Pearson $r$ correlation using GraphPad Prism 7 software.

inactivator CYP3cide and pan-CYP3A inhibitor ketoconazole. Human liver microsomes from single donors genotyped as $C Y P 3 A 5^{*} 1 / * 1(n=$ 4) and $C Y P 3 A 5 * 3 / * 3(n=3)$ were used for this analysis. The difference in the percent inhibition by CYP3cide (CYP3A4-selective inhibitor) versus ketoconazole (pan-CYP3A inhibitor) was used to estimate the CYP3A5 contribution to microsomal M1 formation. The results from this analysis are shown graphically in Fig. 4 and are summarized in Table 1. Notably, the average rate of M1 formation was similar in CYP $3 A 5 * 3 / * 3$ donors $(50 \pm 33 \mathrm{pmol} / \mathrm{min}$ per milligram protein, $n=3$ ) and pooled human liver microsomes from 150 donors $(50 \mathrm{pmol} / \mathrm{min}$ per milligram protein), whereas the average rate of M1 formation was slightly higher among $C Y P 3 A 5 * 1 / * 1$ donors $(65 \pm 29 \mathrm{pmol} / \mathrm{min}$ per milligram protein, $n=4$ ).
In human liver microsomes from $C Y P 3 A 5 * 1 / * 1$ donors $(n=4)$, coincubation with CYP3cide $(2 \mu \mathrm{M})$ reduced M1 formation by $62 \% \pm$ $7 \%$ (mean \pm S.D.) compared with control incubations without inhibitor; ketoconazole reduced M1 levels by $88 \% \pm 3 \%$ compared with control incubations. The estimated average CYP3A5\% contribution among $C Y P 3 A 5 * 1 / * 1$ donors was $26 \% \pm 5 \%$ (range, $20 \%-31 \%$ ). For CYP3A5*3/*3 human liver microsomes $(n=3)$, coincubation with CYP3cide decreased M1 formation by $84 \% \pm 2 \%$ compared with control levels, and ketoconazole reduced debenzylated lapatinib generation by $92 \% \pm 1 \%$, compared with control incubations. The estimated residual CYP3A5 contribution among $C Y P 3 A 5 * 3 / * 3$ donors was $8 \% \pm 2 \%$ (range, $6 \%-10 \%$ ). Collectively, these results demonstrate that the CYP3A5 contribution to lapatinib $O$-debenzylation was 
A

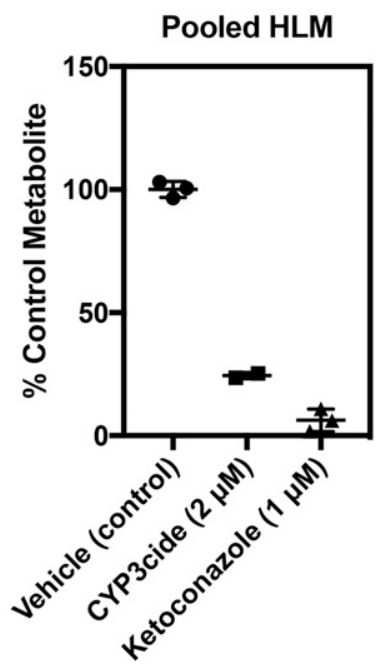

\section{C $C Y P 3 A 5^{*} 1 /{ }^{*} 1 \mathrm{HLM}$}

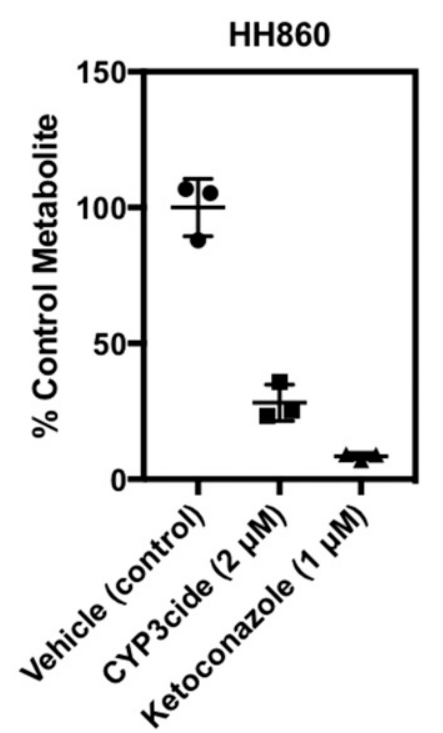

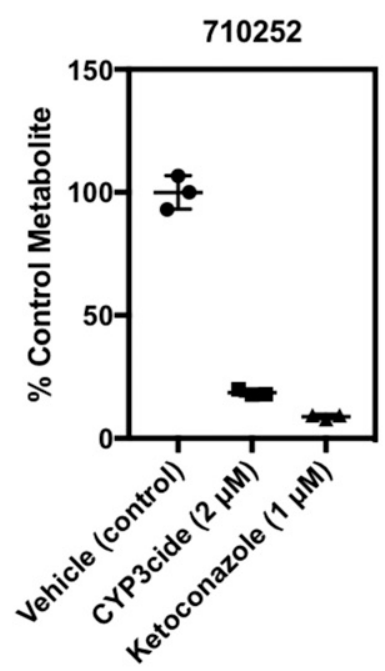
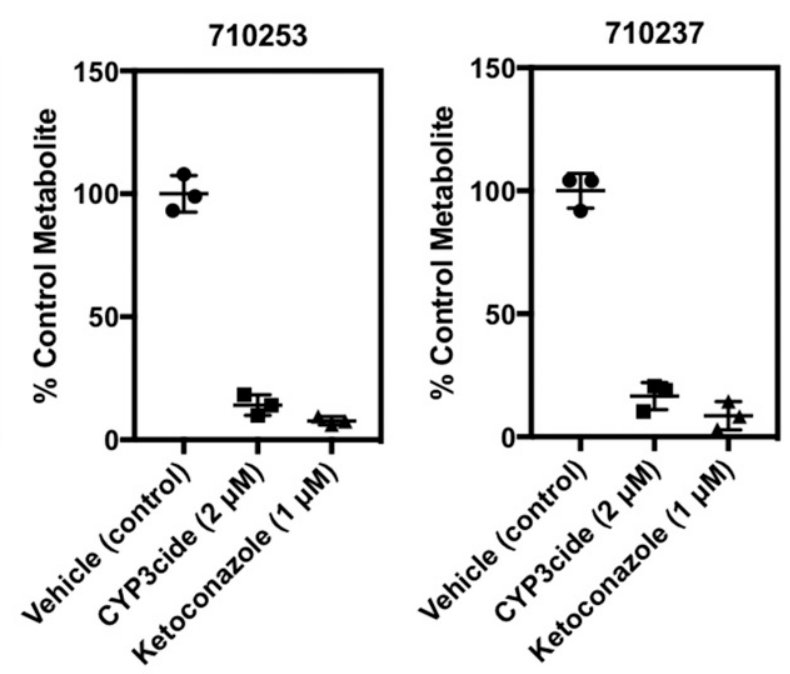

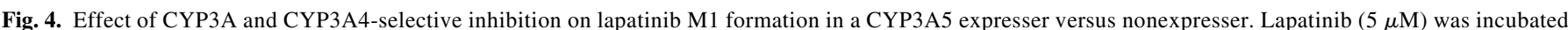

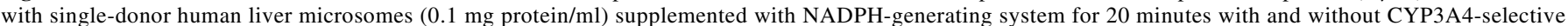

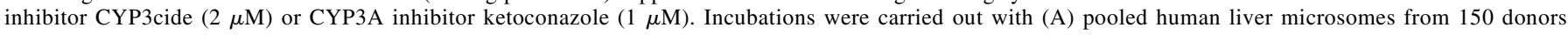

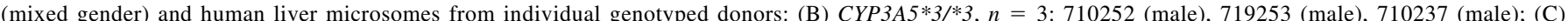

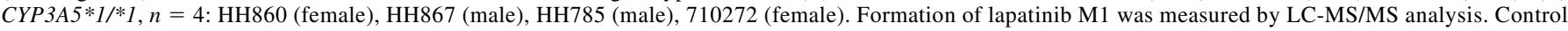

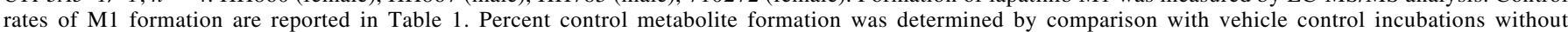

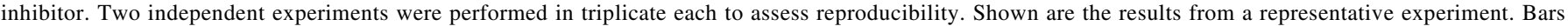
indicate the means, and error bars denote the S.D.

significantly greater in CYP3A5 expressers $(C Y P 3 A 5 * 1 / * 1)$ compared with $C Y P 3 A 5 * 3 / * 3$ donors: $26 \% \pm 5 \%$ versus $8 \% \pm 2 \%(P=0.0022)$. The CYP3A5 contribution to M1 formation in 150-donor pooled human liver microsomes was estimated to be $16 \%$ (Table 1).

Interestingly, the estimated CYP3A5\% contribution to lapatinib M1 formation was positively correlated with microsomal CYP3A5 activity, as measured by T-5 $\mathrm{N}$-oxidation, in the small subset of liver microsomal samples tested $\left(r^{2}=0.87 ; n=7\right)$ (Supplemental Fig. S1). Higher liver microsomal CYP3A5 activity was associated with higher relative CYP3A5 involvement in lapatinib M1 formation.
Lapatinib Metabolism in Genotyped Human Hepatocytes from Pooled Donors. CYP3A activity and lapatinib metabolism were also examined in cryopreserved human hepatocytes from CYP3A5genotyped donors. An initial test was conducted with CYP3A5genotyped hepatocytes pooled from three donors per genotype to evaluate the relationship between CYP3A activity and lapatinib bioactivation in intact cells. Midazolam 1'-hydroxylation was 1.7-2.1fold higher in pooled human hepatocytes from $C Y P 3 A 5 * 1 / * 1$ and CYP $3 A 5 * 1 / * 3$ donors ( 18 and $22 \mathrm{pmol} / \mathrm{min}$ per million cells), respectively, compared with $C Y P 3 A 5 * 3 / * 3$ donors $(10 \mathrm{pmol} / \mathrm{min}$ per million cells) (Fig. 5A). T-5 $\mathrm{N}$-oxidation was $6.5-8.6$-fold greater in 
TABLE 1

Estimation of CYP3A5 contribution to lapatinib $O$-debenzylation (M1 formation) in human liver microsomes (HLMs)from $C Y P 3 A 5$-genotyped donors

\begin{tabular}{|c|c|c|c|c|c|}
\hline HLM & M1 Formation (pmol $/ \mathrm{min}$ per Milligram Protein $)^{a}$ & $\%$ of Control + CYP3cide & $\%$ of Control + Ketoconazole & Estimated \% CYP3A5 Contribution ${ }^{b}$ & $P$ \\
\hline \multicolumn{6}{|l|}{ CYP $3 A 5 * 1 / * 1$} \\
\hline НH860 & $68 \pm 2$ & $28 \pm 7$ & $9 \pm 1$ & 20 & \\
\hline HH867 & $37 \pm 3$ & $42 \pm 4$ & $11 \pm 4$ & 31 & \\
\hline HH785 & $50 \pm 11$ & $42 \pm 3$ & $13 \pm 2$ & 29 & \\
\hline 710272 & $103 \pm 8$ & $40 \pm 4$ & $14 \pm 5$ & 26 & \\
\hline Mean & $65 \pm 29$ & $38 \pm 7$ & $12 \pm 3$ & $26 \pm 5$ & \\
\hline \multicolumn{6}{|l|}{$C Y P 3 A 5 * 3 / * 3$} \\
\hline 710252 & $79 \pm 2$ & $19 \pm 2$ & $9 \pm 1$ & 10 & \\
\hline 710253 & $59 \pm 6$ & $14 \pm 4$ & $8 \pm 2$ & 6 & \\
\hline 710237 & $14 \pm 2$ & $17 \pm 6$ & $9 \pm 6$ & 8 & \\
\hline Mean & $50 \pm 33$ & $16 \pm 2$ & $8 \pm 1$ & $8 \pm 2$ & $0.0022^{c}$ \\
\hline Pooled HLMs & $50 \pm 5$ & $25 \pm 1$ & $9 \pm 3$ & 16 & \\
\hline
\end{tabular}

${ }^{a}$ Formation of debenzylated lapatinib (M1) was quantified by LC-MS/MS analysis using an authentic chemical standard curve, and rates were calculated from control incubations without inhibitor. Values shown are the mean \pm S.D. of triplicate determinations. Mean indicates the mean \pm S.D. rates of M1 formation for $C Y P 3 A 5 * 1 / * 1$ donors $(n=4)$ and $C Y P 3 A 5 * 3 / * 3$ donors $(n=3)$.

${ }^{b}$ Mean percentage (\%) CYP3A5 contribution was estimated based on the difference between inhibition by CYP3cide and ketoconazole.

${ }^{c}$ Mean percentage (\%) CYP3A5 contribution was compared between CYP $3 A 5 * 1 / * 1$ donors $(n=4)$ and $C Y P 3 A 5 * 3 / * 3$ donors $(n=3)$ by unpaired $t$ test using GraphPad Prism 7 software.

pooled hepatocytes from $C Y P 3 A 5 * 1 / * 1$ and $C Y P 3 A 5 * 1 / * 3$ donors $(4.4$ and $5.8 \mathrm{pmol} / \mathrm{min}$ per million cells), respectively, compared with nonexpressers $(C Y P 3 A 5 * 3 / * 3,0.67 \mathrm{pmol} / \mathrm{min}$ per million cells) (Fig. 5B). Relative levels of lapatinib M1 formation were 2.4-fold greater in pooled hepatocytes from $C Y P 3 A 5 * 1 / * 1$ and $C Y P 3 A 5 * 1 / * 3$ donors (CYP3A5 expressers) compared with $C Y P 3 A 5 * 3 / * 3$ donors (Fig. 5C). In this analysis, quinone imine-GSH conjugates were detectable only in hepatocyte incubations from $C Y P 3 A 5^{*} 1 / * 1$ and CYP $3 A 5^{*} 1 / * 3$ donors, which had relatively high CYP3A activity. Quinone imine-GSH conjugates were not detectable in hepatocytes from $C Y P 3 A 5 * 3 / * 3$ donors (data not shown).

Lapatinib Metabolism in Genotyped Human Hepatocytes from Single Donors. To investigate more completely the individual variability in CYP3A activity and lapatinib metabolism, we performed a series of experiments with cryopreserved human hepatocytes from 15 individual $C Y P 3 A 5$-genotyped donors: $C Y P 3 A 5 * 3 / * 3$ donors, $n=8$; $C Y P 3 A 5 * 1 / * 3$ donors, $n=5$; and $C Y P 3 A 5 * 1 / * 1$ donors, $n=2$. Donor demographic information provided by BioIVT is presented in Supplemental Table S1. Midazolam 1'-hydroxylation, a measure of CYP3A activity, varied 37-fold among all donors (1.5-54 pmol/min per million cells), but it did not differ by CYP3A5 genotype (Fig. 6A). $C Y P 3 A 5 * 3 / * 3$ donor JYS (female, Pacific Islander) had the highest rate of 1 '-hydroxymidazolam formation ( $54 \mathrm{pmol} / \mathrm{min}$ per million cells). Of note, this donor was identified as an outlier among $C Y P 3 A 5 * 3 / * 3$ donors with respect to midazolam 1 '-hydroxylation based on Grubbs $(\alpha=0.05)$ outlier identification method (GraphPad Prism 7). Among CYP3A5 expressers, donors RQM $\left(C Y P 3 A 5^{*} 1 / * 1\right.$, female, African American) and OWY $(C Y P 3 A 5 * 1 / * 3$, female, Caucasian $)$, had relatively high rates of midazolam 1 '-hydroxylation at 45 and $42 \mathrm{pmol} / \mathrm{min}$ per million cells, respectively. Rates of the CYP3A5-selective marker reaction, T-5 $\mathrm{N}$-oxidation, were significantly higher in human hepatocyte incubations from $C Y P 3 A 5^{*} 1 / * 1(9.4 \pm 1.5 \mathrm{pmol} / \mathrm{min}$ per million cells, $n=2)$ and CYP3A $5 * 1 / * 3$ donors $(16.4 \pm 9.3 \mathrm{pmol} / \mathrm{min}$ per million cells, $n=5)$ compared with $C Y P 3 A 5 * 3 / * 3$ donors $(1.7 \pm 0.7 \mathrm{pmol} / \mathrm{min}$ per million cells, $n=8$ (one-way ANOVA, $P=0.0017$ ) (Fig. 6B).

Lapatinib metabolism was examined in this same set of genotyped human hepatocytes. Rates of debenzylated lapatinib (M1) formation varied 39-fold among individual hepatocyte donors (range 0.05-2.1 $\mathrm{pmol} / \mathrm{min}$ per million cells, $n=15$ ). Mean rates of midazolam $1^{\prime}$ hydroxylation were 2-fold greater in females compared with males $(27 \pm 19$ vs. $12 \pm 7 \mathrm{pmol} / \mathrm{min}$ per million cells, females $n=7$, males $n=8$, respectively), but this difference was not statistically significant $(P=0.0541)$. Donor JYS had the greatest M1 formation $(2.1 \mathrm{pmol} / \mathrm{min}$ per million cells). In comparison by CYP3A5 genotype, JYS was identified as an outlier among $C Y P 3 A 5 * 3 / * 3$ donors with respect to M1 formation. When JYS was excluded from this analysis as an outlier, the mean M1 formation was greater than 2-fold greater in $C Y P 3 A 5 * 1 / * 1(0.73 \pm 0.43$ $\mathrm{pmol} / \mathrm{min}$ per million cells, $n=2)$ and $C Y P 3 A 5 * 1 / * 3$ donors $(0.66 \pm$ $0.39 \mathrm{pmol} / \mathrm{min}$ per million cells, $n=5$ ) compared with $C Y P 3 A 5 * 3 / * 3$ donors $(0.29 \pm 0.18 \mathrm{pmol} / \mathrm{min}$ per million cells, $n=7)$; however, when JYS was included in the analysis, mean M1 formation among $C Y P 3 A 5 * 3 /$ $* 3$ donors was $0.5 \pm 0.6 \mathrm{pmol} / \mathrm{min}$ per million cells $(n=8)$. There was no statistically significant difference in M1 formation based on CYP3A5 genotype (Fig. 7). When compared by sex, M1 formation was 2.6-fold greater in females $(0.88 \mathrm{pmol} / \mathrm{min}$ per million cells, $n=7)$ compared with males $(0.34 \mathrm{pmol} / \mathrm{min}$ per million cells, $n=8)(P=0.0442)$ (Supplemental Fig. S3A).

Notably, formation of lapatinib M1 was strongly correlated with midazolam 1'-hydroxylation (CYP3A activity) in human hepatocytes among all donors tested $\left(r^{2}=0.87, P<0.0001, n=15\right)$ (Fig. 8A). M1 formation was not correlated with T-5 $N$-oxidation in this set of hepatocyte donors $\left(r^{2}=0.07, P=0.3578, n=15\right)$ (Fig. 8B).

Formation of quinone imine-GSH conjugates from lapatinib was also examined in CYP3A5-genotyped single-donor human hepatocytes. Quinone imine-GSH conjugates were detectable from incubations with 8 of the 15 individual donors (Supplemental Fig. S2B). This result may be due to the limited sensitivity of our LC-MS/MS method to detect reactive metabolite-GSH conjugates generated in intact hepatocytes from lapatinib at a substrate concentration of $10 \mu \mathrm{M}$. Among the samples with detectable quinone imine-GSH conjugates, the relative levels varied among individual donors (0.001-0.04 peak area ratio, $n=8$ ). Similar to lapatinib M1, quinoneimine-GSH conjugate formation was significantly correlated with CYP3A activity, as measured by midazolam $1^{\prime}$-hydroxylation $\left(r^{2}=0.76, P=0.0045, n=8\right)$ (Fig. 9A); however, quinoneimine-GSH conjugate formation was not correlated with CYP3A5-selective activity, as measured by T-5 N-oxidation $\left(r^{2}=0.06, P=0.5678, n=8\right)$ (Fig. 9B). Among the hepatocyte donors tested, donor JYS $(C Y P 3 A 5 * 3 / * 3)$ had the highest levels of M1 and quinone imine-GSH conjugates, as well as the highest level of CYP3A activity (formation of 1'-hydroxymidazolam).

Effect of CYP3A and CYP3A4-Selective Inhibition on Lapatinib Metabolism in Genotyped Hepatocytes. Selective CYP3A chemical inhibitors were also used to estimate the contributions of CYP3A4 and CYP3A5 to lapatinib $O$-debenzylation in human hepatocytes from CYP3A5-genotyped donors. Two donors with the highest relative levels of lapatinib M1 formation were selected for comparison based on genotype and enzyme activity: JYS and OWY. Donor JYS (CYP3A5*3/*3) had low CYP3A5 activity, as indicated by the rate of T-5 $\mathrm{N}$-oxidation 
A

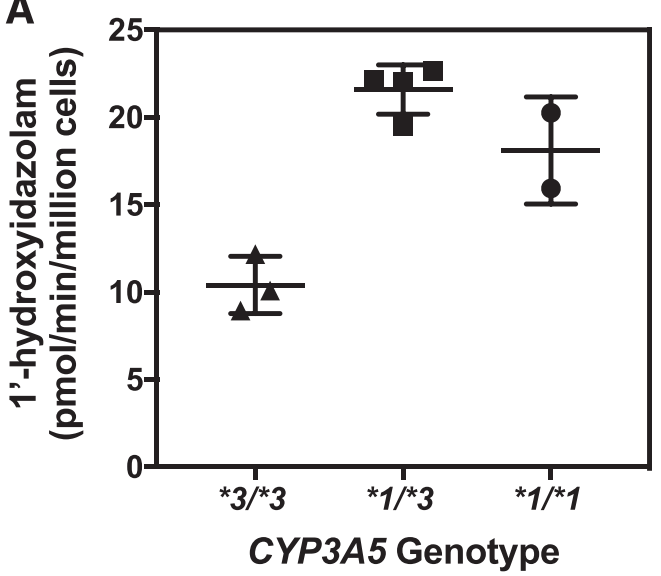

B

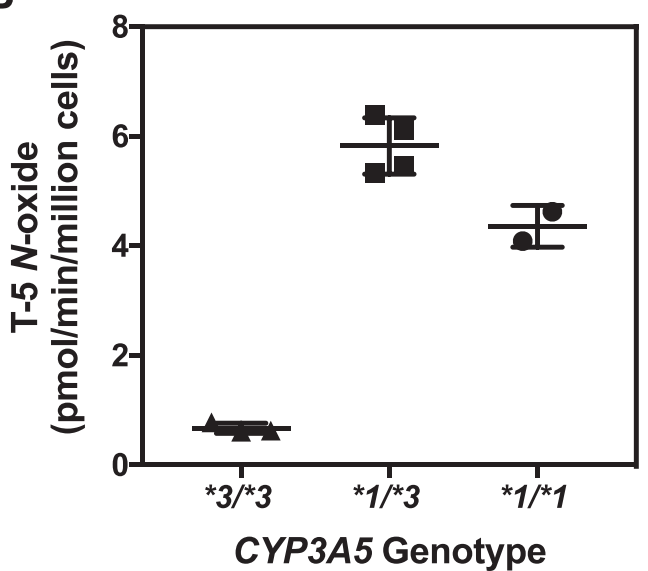

C

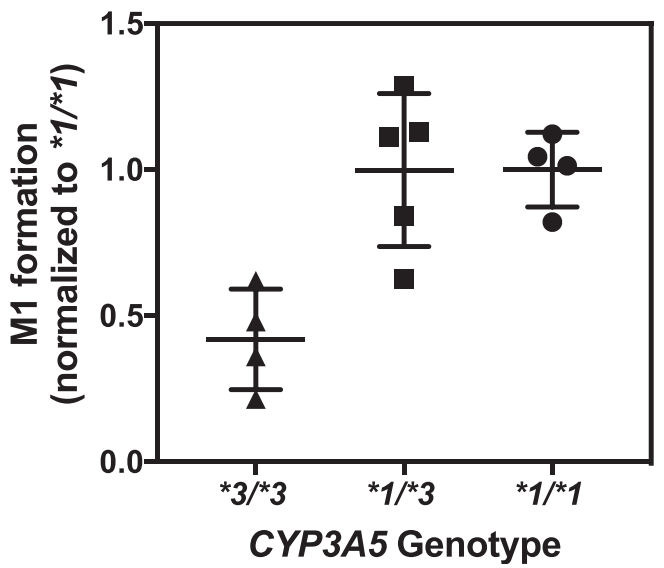

Fig. 5. Midazolam 1 '-hydroxylation, T-5 $N$-oxidation, and lapatinib $O$-debenzylation in pooled human hepatocytes. Genotyped human hepatocytes were from a pool of three donors each. (A) Midazolam $(2.5 \mu \mathrm{M})$ and (B) T-5 $(5 \mu \mathrm{M})$ were incubated with hepatocytes $\left(0.5 \times 10^{6}\right.$ cells $\left./ \mathrm{ml}\right)$ in suspension for 30 minutes. (C) Lapatinib $(10 \mu \mathrm{M})$ was incubated with hepatocytes $\left(0.5 \times 10^{6}\right.$ cells $\left./ \mathrm{ml}\right)$ in suspension for 2 hours. Formation of 1 '-hydroxymidazolam, T-5 N-oxide, and lapatinib M1 was measured by LC-MS/MS analysis. Relative levels of M1 were determined by the ratio of M1 to lapatinib peak areas and normalized to $C Y P 3 A 5 * 1 / * 1$ donors. Each point is from a single experiment performed in replicate (two to four). The mean is indicated by the line, and errors are the S.D.

(selective marker of CYP3A5 activity) at $3.0 \mathrm{pmol} / \mathrm{min}$ per million cells. Donor OWY $(C Y P 3 A 5 * 1 / * 3)$ had relatively high CYP3A5 activity, as indicated by a rate of T-5 N-oxidation at $19.5 \mathrm{pmol} / \mathrm{min}$ per million cells (Fig. 6B). As noted already, total CYP3A activity, measured by midazolam 1'-hydroxylation, was similar in donors JYS and OWY
A

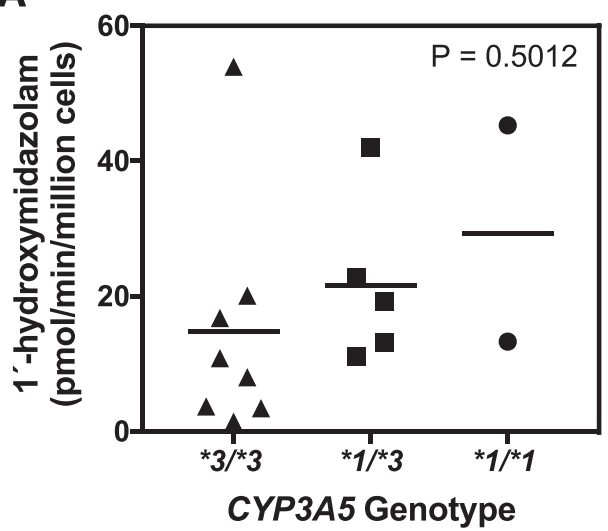

B

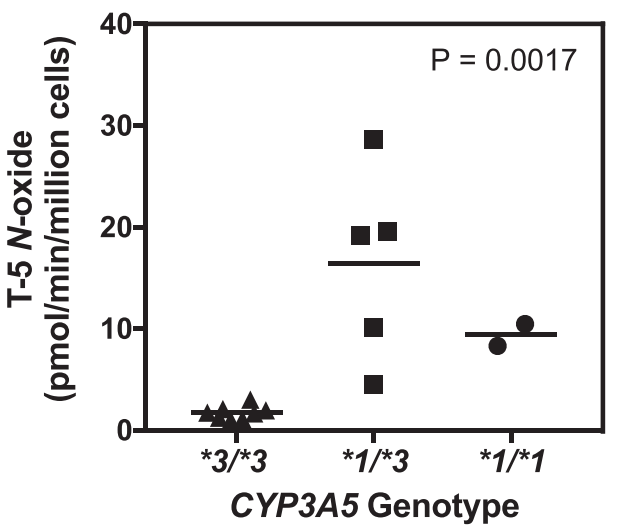

Fig. 6. CYP3A and CYP3A5-selective activity in genotyped single-donor human hepatocytes. (A) Midazolam $(2.5 \mu \mathrm{M})$ and (B) T-5 $(5 \mu \mathrm{M})$ were incubated with hepatocytes $\left(0.5 \times 10^{6}\right.$ cells $\left./ \mathrm{ml}\right)$ in suspension for 30 minutes. Formation of $1^{\prime}$-hydroxymidazolam (A) and T-5 N-oxide (B) was measured by LC-MS/MS analysis. Results are the mean values for each donor from experiments performed in triplicate. $C Y P 3 A 5 * 3 / * 3$ donors, $n=8 ; C Y P 3 A 5 * 1 / * 3$ donors, $n=5 ; C Y P 3 A 5 * 1 / * 1$ donors, $n=2$. Comparison one-way ANOVA (GraphPad Prism 7).

(54 and $42 \mathrm{pmol} / \mathrm{min}$ per million cells, respectively) (Fig. 6A). In hepatocyte incubations from JYS (CYP3A5 nonexpresser), coincubation with the CYP3A4-selective inactivator CYP3cide reduced lapatinib M1 formation by $94 \%$ compared with vehicle control. The pan-CYP3A

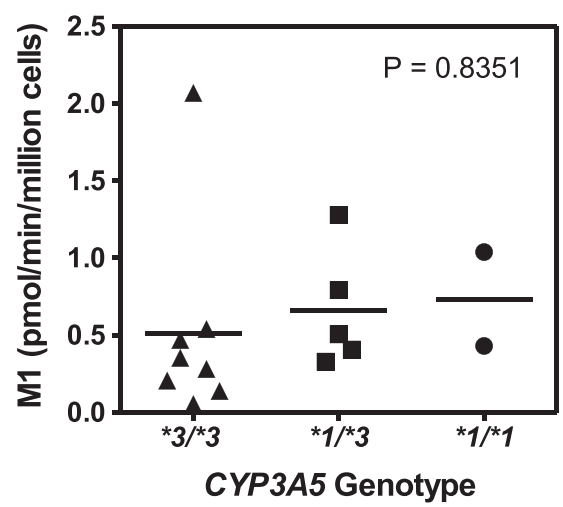

Fig. 7. Lapatinib M1 formation in genotyped single-donor human hepatocytes. Lapatinib $(10 \mu \mathrm{M})$ was incubated with hepatocytes $\left(0.5 \times 10^{6}\right.$ cells $\left./ \mathrm{ml}\right)$ in suspension for 2.2 hours. Formation of lapatinib M1 was quantified by LC-MS/MS analysis using a standard curve. Results are the mean values for each donor from experiments performed in triplicate. CYP3A $5 * 3 / * 3$ donors, $n=8 ; C Y P 3 A 5 * 1 / * 3$ donors, $n=5$; CYP $3 A 5 * 1 / * 1$ donors, $n=2$. M1 formation is plotted by CYP3A5 genotype. 


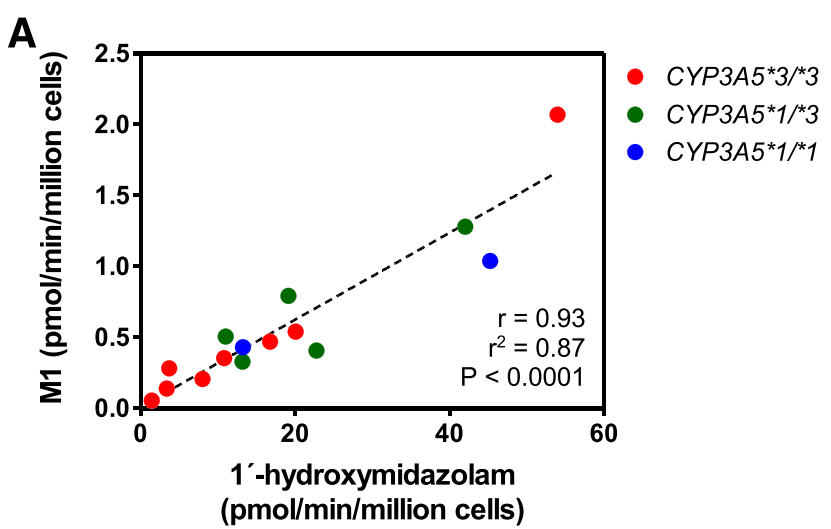

B

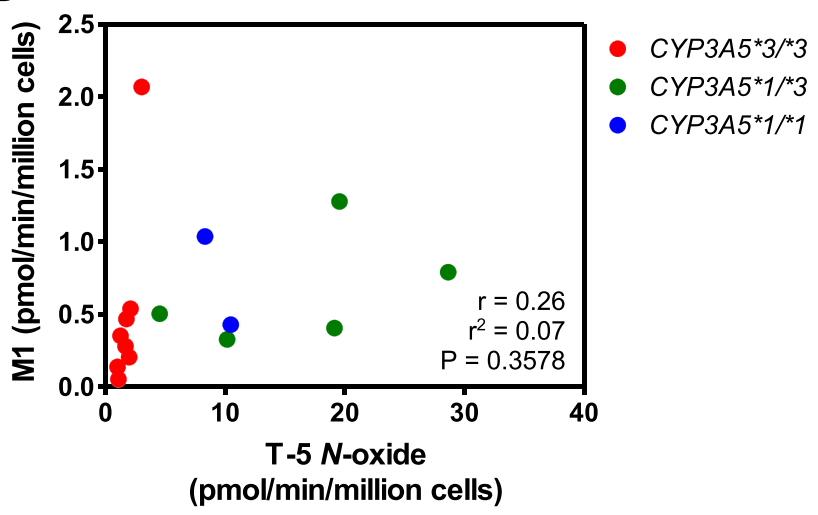

Fig. 8. Correlation of lapatinib M1 formation with CYP3A and CYP3A5-selective activity in genotyped single-donor human hepatocytes. Formation of M1 was analyzed for correlation with midazolam $1^{\prime}$-hydroxylation (A) and T-5 N-oxidation (B). Results are the mean values for each donor from experiments performed in triplicate. The total human liver donors were $n=15$. CYP $3 A 5 * 3 / * 3$ donors, $n=8$; $C Y P 3 A 5 * 1 / * 3$ donors, $n=5 ; C Y P 3 A 5 * 1 / * 1$ donors, $n=2$. Linear regression analysis was performed to determine $r^{2}$ and Pearson $r$ correlation using GraphPad Prism 7.

inhibitor ketoconazole reduced M1 formation by 95\% (Fig. 10A), indicating that lapatinib M1 formation was predominantly mediated by CYP3A4. In hepatocyte incubations with OWY (CYP3A5 expresser), CYP3cide decreased levels of M1 by $45 \%$, whereas ketoconazole reduced M1 levels by $87 \%$ compared with vehicle control (Fig. 10B). This finding suggests that the remaining hepatic CYP3A5 activity contributed $42 \%$ to lapatinib M1 formation in CYP3A5 expresser OWY.

Additional Metabolites of Lapatinib. We also examined lapatinib metabolism via non-P450 pathways as potentially competing routes of biotransformation in primary human hepatocytes. The hydroxylated metabolite of lapatinib (AO-M1), proposed by Dick (2018), and hydroxylated debenzylated lapatinib (M3) were observed in hepatocyte incubations. Relative levels of AO-M1 did not differ between CYP3A5 expressers and nonexpressers. An inverse relationship was observed between formation of debenzylated lapatinib (M1) and AO-M1 in human hepatocytes from individual donors $\left(r=-0.62 ; r^{2}=0.38, P=\right.$ 0.0145) (Supplemental Fig. S4). To confirm the role of AO in generating the hydroxylated metabolite of lapatinib (AO-M1) and the hydroxylated metabolite of debenzylated lapatinib M3, we conducted experiments with human liver S9 fraction, which contains both microsomal and cytosolic enzymes. Preincubation with the AO inhibitor hydralazine $(25 \mu \mathrm{M})$ reduced the formation of AO-M1 from lapatinib by $99 \%$ compared with control incubations without inhibitor. Hydralazine also reduced M3 formation from debenzylated lapatinib by $92 \%$ compared with control. The xanthine oxidase inhibitor (and AO substrate) allopurinol $(100 \mu \mathrm{M})$ decreased AO-M1 formation by $27 \%$ compared with control and had a minimal effect on M3. These data demonstrate that AO catalyzes the oxidation of lapatinib and debenzylated lapatinib to AO-M1 and M3, respectively (Fig. 11; Supplemental Fig. S5).

\section{Discussion}

CYP3A4 and CYP3A5 are the primary enzymes responsible for oxidative metabolism of lapatinib via $O$-debenzylation, leading to formation of an electrophilic quinone imine; this pathway has been implicated in the development of lapatinib-induced liver injury (Teng et al., 2010; Takakusa et al., 2011; Castellino et al., 2012). We hypothesized that $C Y P 3 A 5$ genotype would have a significant impact on the generation of reactive metabolites from lapatinib; however, the findings of the present study indicate that lapatinib bioactivation is highly correlated with total hepatic CYP3A activity, and not CYP3A5 genotype alone. Formation of debenzylated lapatinib (M1) was significantly correlated with CYP3A activity (midazolam 1'-hydroxylation) in human liver microsomes $\left(r^{2}=0.75\right)$ (Fig. 3) and primary human hepatocytes $\left(r^{2}=0.87\right)$ (Fig. 8). Relative levels of quinone imine-GSH conjugates were also strongly correlated with midazolam $1^{\prime}$-hydroxylation in human liver microsomes $\left(r^{2}=0.91\right)$ (Fig. 3) and human hepatocytes $\left(r^{2}=0.76\right)$ (Fig. 9).

Wide interindividual variation in CYP3A activity was observed in this study; midazolam 1'-hydroxylation varied 76-fold and 37-fold in human liver microsomes and primary human hepatocytes, respectively, which is consistent with previous reports. Moreover, lapatinib $O$-debenzylation
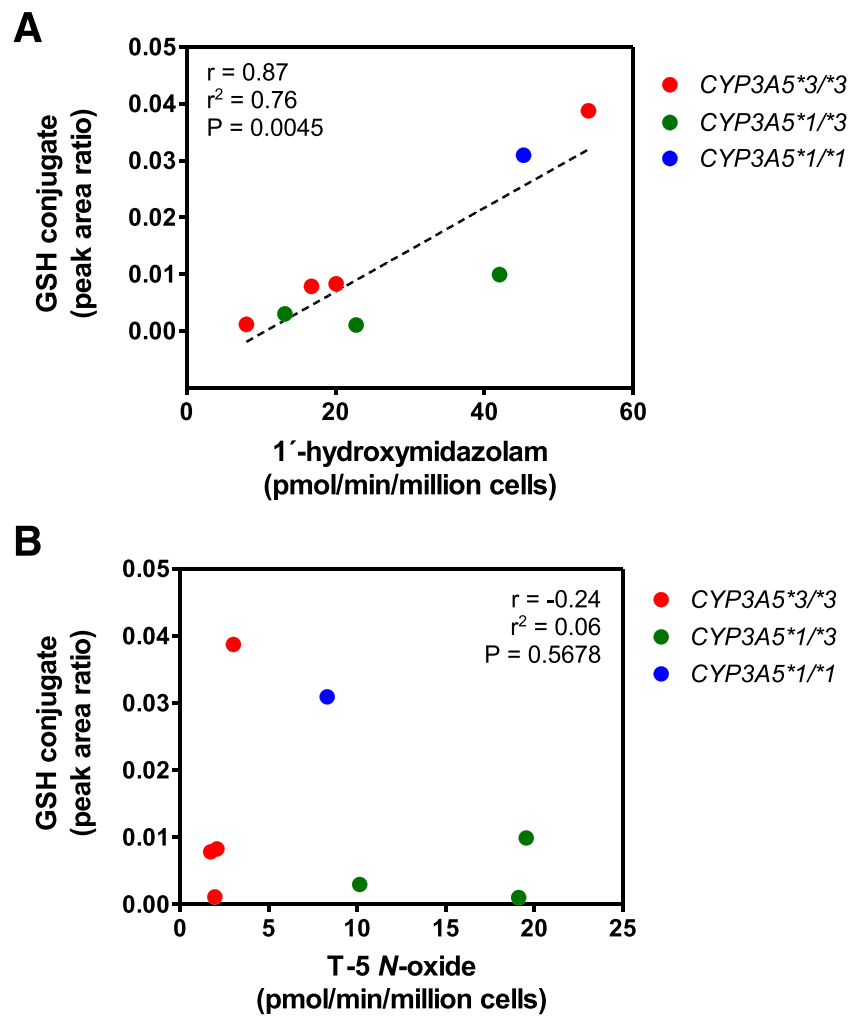

Fig. 9. Lapatinib quinone imine-GSH conjugate formation in genotyped human hepatocytes and correlation with CYP3A and CYP3A5-selective activity. Relative levels of quinone imine-GSH conjugates (peak area/internal standard peak area) were measured by LC-MS/MS analysis. Formation of quinone imine-GSH conjugates was analyzed for correlation with midazolam 1'-hydroxylation (A) and T-5 $N$-oxidation (B). Results are the mean values for each donor from experiments performed in triplicate. The total human liver donors with detectable quinone imine-GSH conjugates was eight. $C Y P 3 A 5 * 3 / * 3$ donors, $n=4 ; C Y P 3 A 5 * 1 /$ $* 3$ donors, $n=3$; CYP $3 A 5 * 1 / * 1$ donor, $n=1$. Linear regression analysis was performed to determine $r^{2}$ and Pearson $r$ correlation using GraphPad Prism 7. 


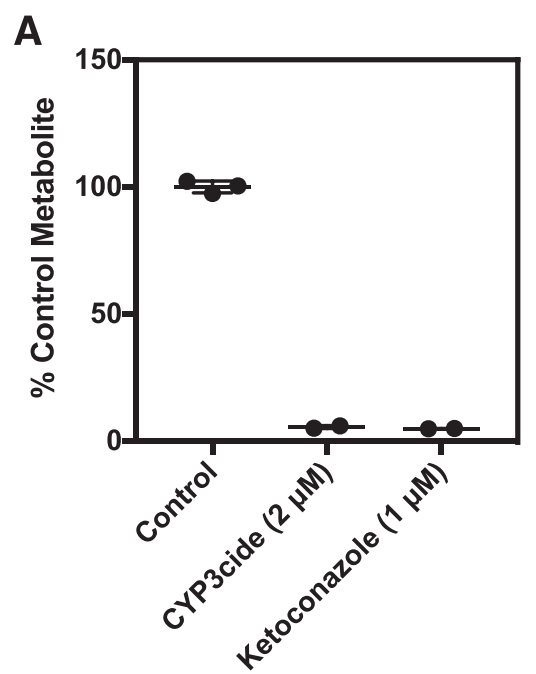

B

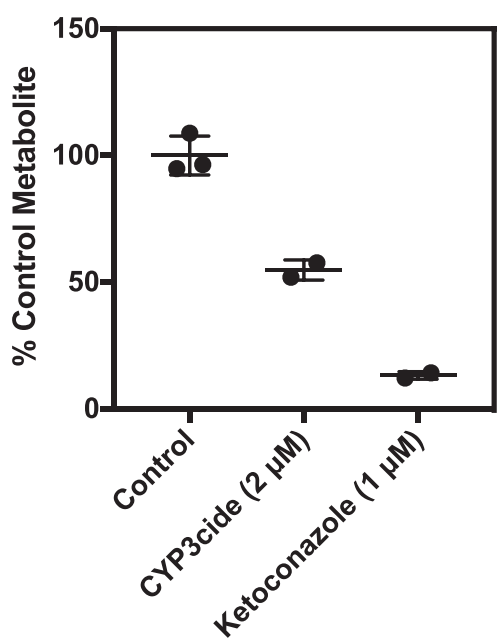

Fig. 10. Effect of CYP3A and CYP3A4-selective inhibition on lapatinib M1 formation in a CYP3A5 expresser versus nonexpresser. Lapatinib $(10 \mu \mathrm{M})$ was incubated with hepatocytes $\left(0.5 \times 10^{6}\right.$ cells $\left./ \mathrm{ml}\right)$ in suspension for 2.2 hours with and without CYP3A4-selective inhibitor CYP3cide $(2 \mu \mathrm{M})$ or CYP3A inhibitor ketoconazole $(1 \mu \mathrm{M})$. Relative levels of lapatinib M1 were measured by LC-MS/ MS analysis. Results are the mean and S.D. from a single experiment performed in duplicate or triplicate. (A) Donor JYS, CYP3A5 nonexpresser $(C Y P 3 A 5 * 3 / * 3)$. (B) Donor OWY, CYP3A5 expresser $(C Y P 3 A 5 * 1 / * 3)$.

varied 7-fold in individual human liver microsomes and 39-fold in primary human hepatocytes from individual donors. Lin et al. (2002) reported 68-fold variation in total hepatic CYP3A protein content in human liver microsomes from 60 Caucasian donors, and midazolam 1'hydroxylation varied 28-fold among these donors. Lamba et al. (2002) reported that CYP3A expression can vary 40-fold in human liver and intestine. Genetic and nongenetic factors influence CYP3A activity (Klein and Zanger, 2013; Zanger and Schwab, 2013). Variation in nuclear receptors that regulate CYP3A4 expression (e.g., pregnane $\mathrm{X}$ receptor, constitutive androstane receptor) contribute to interindividual variability in CYP3A activity (Lamba et al., 2010; Zanger and Schwab, 2013). Enzyme induction and inhibition, epigenetics, and disease states also influence CYP3A activity (Zanger and Schwab, 2013). Conflicting results have been reported regarding gender differences in CYP3A activity (i.e., males vs. females) (Lin et al., 2002; Yang et al., 2010; Achour et al., 2014). In the present study, females had 2-fold greater CYP3A activity (midazolam 1'-hydroxylation) compared with males in hepatocyte incubations, but this difference was not statistically significant $(P=0.0541)$. Hepatocytes from female donors formed 2.6-fold higher levels of lapatinib M1 compared with males $(P=0.0442)$.

The CYP3A5-selective marker reaction T-5 $N$-oxidation, described by $\mathrm{Li}$ et al. (2014), was used to characterize CYP3A5 activity in CYP3A5-genotyped human liver microsomal samples and cryopreserved human hepatocytes. T- $5 \mathrm{~N}$-oxidation was significantly associated with the CYP3A5 genotype in human liver microsomes (Fig. 1) and in primary human hepatocytes (Fig. 6), indicating a strong CYP3A5 genotype/phenotype relationship. Individual livers carrying at least one CYP3A5*1 allele had significantly greater CYP3A5 activity compared with livers homozygous for $C Y P 3 A 5 * 3$. Formation of lapatinib M1 was correlated with T-5 $N$-oxidation in human liver microsomes $\left(r^{2}=0.51\right)$ (Fig. 3), but not in primary human hepatocytes $\left(r^{2}=0.07\right)$ (Fig. 8). The reason for this discrepancy between microsomes and hepatocytes is not known and warrants further investigation. Relative levels of quinone imine-GSH conjugates were not associated with CYP3A5 activity (T-5 $N$-oxidation) in human liver microsomes $\left(r^{2}=0.32\right)$ (Fig. 3) or primary human hepatocytes $\left(r^{2}=0.06\right)$ (Fig. 9). Formation of lapatinib $\mathrm{M} 1$ and quinone imine-GSH conjugates did not differ significantly by CYP3A5 genotype (Fig. 2). These results indicate that CYP3A5 genotype and activity alone are not predictive of lapatinib bioactivation.

CYP3A4 and CYP3A5 contributions to lapatinib $O$-debenzylation were estimated in human liver microsomes and cryopreserved hepatocytes based on the percent inhibition by CYP3cide (CYP3A4-selective inactivator) compared with inhibition by ketoconazole (CYP3A-pan inhibitor), as described previously (Walsky et al., 2012; Tseng et al., 2014). The contributions of CYP3A4 versus CYP3A5 to lapatinib $O$-debenzylation varied by individual, but CYP3A4 played a dominant role in lapatinib metabolism in all donors. Of the total CYP3A contribution, CYP3A4 contributed more than $90 \%$ on average to lapatinib M1 formation in $C Y P 3 A 5 * 3 / * 3$ livers. The estimated CYP3A4 contribution was approximately $60 \%-75 \%$ in livers homozygous or heterozygous for $C Y P 3 A 5 * 1$. CYP3A5 contributed an estimated $20 \%-42 \%$ to $\mathrm{M} 1$ formation in livers from individuals carrying the $C Y P 3 A 5 * 1$ allele. In addition to the $O$-debenzylation pathway, lapatinib is metabolized via $N$-hydroxylation and $N$-dealkylation predominately by CYP3A4 (Takakusa et al., 2011). Differential interactions of lapatinib with CYP3A4 and CYP3A5 can have unique effects on enzyme activity and product regioselectivity (Takakusa et al., 2011; Chan et al., 2012; Barbara et al., 2013). Lapatinib is a time-dependent inhibitor of CYP3A4 through metabolic-intermediate complex formation, which is thought to occur primarily by lapatinib $N$-hydroxylation and subsequent oxidation to a nitroso intermediate (Takakusa et al., 2011). In contrast, inactivation of CYP3A5 by lapatinib may occur through adduction of the quinone imine to the apoprotein (Chan et al., 2012).

To our knowledge, this is the first study to examine the effect of CYP3A5 genotype, CYP3A5-selective activity, and total CYP3A activity on lapatinib bioactivation in individual human liver tissues from multiple donors. The dominant role of CYP3A4 in lapatinib bioactivation observed in the present study is consistent with previous studies. In kinetic analyses with recombinant CYP3A4 and CYP3A5, recombinant $\mathrm{CYP} 3 \mathrm{~A} 4$ was 5 -fold more efficient at lapatinib $O$-debenzylation and 4-fold more efficient at generating quinone imine-GSH conjugates compared with recombinant CYP3A5 (Towles et al., 2016). Inhibition studies with pooled human liver microsomes demonstrated that CYP3A5 contributed $16 \%-22 \%$ to generating quinone imine-GSH conjugates (Towles et al., 2016). Previous studies reported that CYP3A5 genotype may influence the levels of quinone imine-GSH conjugates formed in vitro (Chan et al., 2014; Ho et al., 2015); however, these findings have not been replicated in vivo. As noted previously, wide (39-fold) interindividual variation in lapatinib $O$-debenzylation was observed in the present study and 
<smiles>CS(=O)(=O)CCNCc1ccc(-c2ccc3ncnc(Nc4ccc(OCc5cccc(F)c5)c(Cl)c4)c3c2)o1</smiles>

Lapatinib

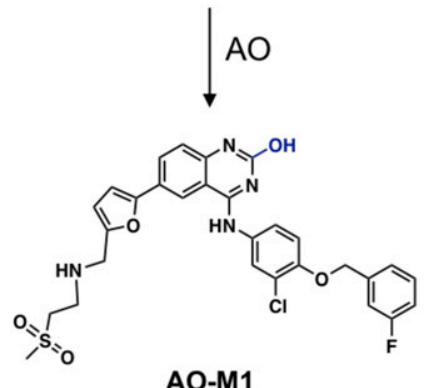

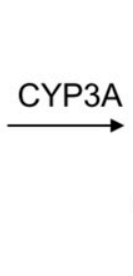

is:o

Debenzylated lapatinib

(M1)

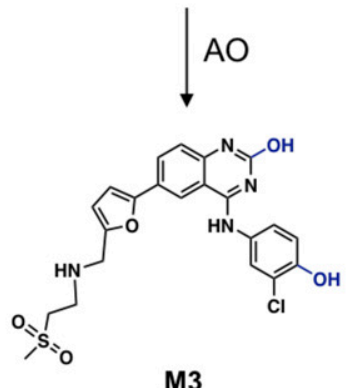

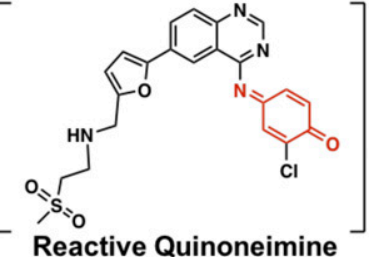

Reactive Quinoneimine

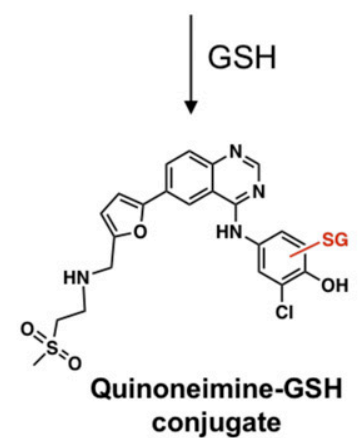

Fig. 11. Lapatinib metabolism: CYP3A-mediated bioactivation vs. aldehyde oxidase-mediated pathway.

was highly associated with CYP3A activity. This result suggests that measuring individual CYP3A phenotype, and not CYP3A5 genotype alone, may be an important approach to assess individual drug metabolism status more accurately and improve precision dosing.

Lapatinib pharmacokinetics exhibit high interindividual variability in cancer patients, and variation in CYP3A-mediated metabolism is suggested to contribute, at least in part, to differences in lapatinib exposure (Burris et al., 2005). Because CYP3A-mediated $O$-debenzylation is a major route of lapatinib metabolism, factors that alter CYP3A expression and activity likely have a significant impact on the extent of lapatinib bioactivation. In addition, non-P450 pathways may contribute to lapatinib metabolism and variability in drug exposure. Consistent with the recent findings by Dick (2018), we have shown that aldehyde oxidase catalyzes hydroxylation of lapatinib to AO-M1 and oxidation of lapatinib M1 to M3, a major metabolite excreted in vivo (Fig. 11) (Castellino et al., 2012). Further, lapatinib is a substrate for efflux transporters P-glycoprotein (ABCB1) and breast cancer resistance protein, and lapatinib is an inhibitor of P-glycoprotein, breast cancer resistance protein, and organic anion transporting polypeptide $1 \mathrm{~B} 1$ at clinically relevant concentrations (Polli et al., 2008). Lapatinib M1 was suggested to be an inhibitor of the bile salt export pump (Castellino et al., 2012). Further research is needed to assess the role of altered drug metabolism and transport on the risk of lapatinib-induced hepatotoxicity in the clinical setting.

An association between CYP3A4 genotype, protein abundance, and/ or activity and drug exposure has been shown for other clinically relevant tyrosine kinase inhibitors. Using midazolam as a CYP3A phenotyping probe in cancer patients, Barr et al. (2014) and de Wit et al. (2014) demonstrated that sunitinib exposure significantly correlated with midazolam exposure; intestinal and hepatic CYP3A activity was proposed to explain approximately $40 \%-50 \%$ of the interpatient viability in sunitinib exposure. Presence of the CYP3A4 reducedfunction allele $* 22$ reduced pazopanib clearance in simulated cancer patients compared with patients with wildtype CYP3A4 (Bins et al., 2019). Moreover, using a physiologically based pharmacokinetic model, Sorich et al. (2019) reported that CYP3A abundance was the dominant factor affecting variability in exposure to axitinib. Together, these studies indicate that CYP3A phenotype may have a significant influence on the pharmacokinetics of tyrosine kinase inhibitors and other classes of drugs predominately metabolized by CYP3A.
Limitations of this study include the small sample size and limited genetic information. Commercially available $C Y P 3 A 5$-genotyed human liver microsomes and cryopreserved hepatocytes are in limited supply, especially among donors expressing CYP3A5. The human liver samples included in this study were genotyped for $C Y P 3 A 5 * 1$ and $* 3$ alleles, but not CYP3A5 variant alleles $* 6$ and $* 7$, which also cause reduced CYP3A5 expression (Kuehl et al., 2001). Livers were not genotyped for $C Y P 3 A 4 * 22$, which is linked to reduced CYP3A4 mRNA levels and enzymatic activity (Wang et al., 2011; Wang and Sadee, 2016). CYP3A4 and CYP3A5 protein levels and mRNA expression were not analyzed; however, measurement of CYP3A and CYP3A5-selective activity using established probe substrates and marker reactions provided a relevant indicator of CYP3A functional status. Donor JYS was identified as an outlier among $C Y P 3 A 5 * 3 / * 3$ donors with respect to $C Y P 3 A$ activity and lapatinib metabolism. The medical history of this and other donors is not known; thus, we do not know whether donors were taking medications or dietary supplements that alter CYP3A activity. Additional information is needed to understand why this donor (JYS) had relatively high CYP3A activity; however, such information is not available because of privacy restrictions.

In summary, the results of this study indicate that total CYP3A activity is a major determinant of the extent of lapatinib bioactivation. Interindividual variation in lapatinib metabolic activation was highly correlated to individual CYP3A activity. Factors that influence CYP3A activity likely affect individual exposure to reactive, potentially toxic metabolites of lapatinib. Future studies are warranted to assess the utility of CYP3A phenotyping in vivo to guide lapatinib dosing and predict the risk of lapatinib toxicity in clinical settings.

\section{Acknowledgments}

We thank Dr. Michael Cameron (Scripps Research Institute) for providing T-5 (T-1032) and T-5 $N$-oxide standards for CYP3A5 phenotyping studies; Dr. F. Peter Guengerich and his group (Vanderbilt University) for valuable scientific discussions during the manuscript preparation; and Dr. Matthew Vergne for assistance with LC-MS/MS instrumentation in the Lipscomb University College of Pharmacy Bioanalytical Core Laboratory.

\section{Authorship Contributions}

Participated in research design: Bissada, Abouda, Wines, Crouch, Jackson. Conducted experiments: Bissada, Truong, Abouda, Wines, Crouch, Jackson. 
Performed data analysis: Bissada, Truong, Abouda, Wines, Crouch, Jackson. Wrote or contributed to the writing of the manuscript: Bissada, Truong, Abouda, Crouch, Jackson.

\section{References}

Achour B, Barber J, and Rostami-Hodjegan A (2014) Expression of hepatic drug-metabolizing cytochrome p450 enzymes and their intercorrelations: a meta-analysis. Drug Metab Dispos 42 : $1349-1356$.

Amaya GM, Durandis R, Bourgeois DS, Perkins JA, Abouda AA, Wines KJ, Mohamud M, Starks SA, Daniels RN, and Jackson KD (2018) Cytochromes P450 1A2 and 3A4 catalyze the metabolic activation of sunitinib. Chem Res Toxicol 31:570-584.

Aoyama T, Yamano S, Waxman DJ, Lapenson DP, Meyer UA, Fischer V, Tyndale R, Inaba T, Kalow W, Gelboin HV, et al. (1989) Cytochrome P-450 hPCN3, a novel cytochrome P-450 IIIA gene product that is differentially expressed in adult human liver. cDNA and deduced amino acid sequence and distinct specificities of cDNA-expressed hPCN1 and hPCN3 for the metabolism of steroid hormones and cyclosporine. J Biol Chem 264:10388-10395.

Azim HA Jr, Agbor-Tarh D, Bradbury I, Dinh P, Baselga J, Di Cosimo S, Greger JG Jr, Smith I, Jackisch C, Kim SB, et al. (2013) Pattern of rash, diarrhea, and hepatic toxicities secondary to lapatinib and their association with age and response to neoadjuvant therapy: analysis from the NeoALTTO trial. J Clin Oncol 31:4504-4511.

Barbara JE, Kazmi F, Parkinson A, and Buckley DB (2013) Metabolism-dependent inhibition of CYP3A4 by lapatinib: evidence for formation of a metabolic intermediate complex with a nitroso/ oxime metabolite formed via a nitrone intermediate. Drug Metab Dispos 41:1012-1022.

Barr JT, Choughule KV, Nepal S, Wong T, Chaudhry AS, Joswig-Jones CA, Zientek M, Strom SC, Schuetz EG, Thummel KE, et al. (2014) Why do most human liver cytosol preparations lack xanthine oxidase activity? Drug Metab Dispos 42:695-699.

Bins S, Huitema ADR, Laven P, Bouazzaoui SE, Yu H, van Erp N, van Herpen C, Hamberg P, Gelderblom H, Steeghs N, et al. (2019) Impact of CYP3A4*22 on pazopanib pharmacokinetics in cancer patients. Clin Pharmacokinet 58:651-658.

Birdwell KA, Decker B, Barbarino JM, Peterson JF, Stein CM, Sadee W, Wang D, Vinks AA, He Y, Swen JJ, et al. (2015) Clinical pharmacogenetics implementation consortium (CPIC) guidelines for CYP3A5 genotype and tacrolimus dosing. Clin Pharmacol Ther 98:19-24.

Burris HA III, Hurwitz HI, Dees EC, Dowlati A, Blackwell KL, O'Neil B, Marcom PK, Ellis MJ, Overmoyer B, Jones SF, et al. (2005) Phase I safety, pharmacokinetics, and clinical activity study of lapatinib (GW572016), a reversible dual inhibitor of epidermal growth factor receptor tyrosine kinases, in heavily pretreated patients with metastatic carcinomas. J Clin Oncol 23:5305-5313.

Castellino S, O'Mara M, Koch K, Borts DJ, Bowers GD, and MacLauchlin C (2012) Human metabolism of lapatinib, a dual kinase inhibitor: implications for hepatotoxicity. Drug Metab Dispos 40:139-150.

Chan ECY, New LS, Chua TB, Yap CW, Ho HK, and Nelson SD (2012) Interaction of lapatinib with cytochrome P450 3A5. Drug Metab Dispos 40:1414-1422.

Chan JCY, Choo DYM, and Chan ECY (2014) Impact of CYP3A5 genetic polymorphism on mechanism-based inactivation by lapatinib, in 19th North American International Society for the Study of Xenobiotics (ISSX) and 29th Japanese Society for the Study of Xenobiotics (JSSX Joint Meeting;2014 Oct 19-23; San Francisco, CA. Supp 9(2), Abstract P287. International Society for the Study of Xenobiotics, Washington, DC.

Dennison JB, Jones DR, Renbarger JL, and Hall SD (2007) Effect of CYP3A5 expression on vincristine metabolism with human liver microsomes. J Pharmacol Exp Ther 321:553-563.

de Wit D, Gelderblom H, Sparreboom A, den Hartigh J, den Hollander M, König-Quartel JM, Hessing T, Guchelaar HJ, and van Erp NP (2014) Midazolam as a phenotyping probe to predict sunitinib exposure in patients with cancer. Cancer Chemother Pharmacol 73:87-96.

Dick RA (2018) Refinement of in vitro methods for identification of aldehyde oxidase substrates reveals metabolites of kinase inhibitors. Drug Metab Dispos 46:846-859.

Gomez HL, Doval DC, Chavez MA, Ang PC, Aziz Z, Nag S, Ng C, Franco SX, Chow LW, Arbushites MC, et al. (2008) Efficacy and safety of lapatinib as first-line therapy for ErbB2 amplified locally advanced or metastatic breast cancer. J Clin Oncol 26:2999-3005.

Goss PE, Smith IE, O'Shaughnessy J, Ejlertsen B, Kaufmann M, Boyle F, Buzdar AU, Fumoleau P, Gradishar W, Martin M, et al.; TEACH Investigators (2013) Adjuvant lapatinib for women with early-stage HER2-positive breast cancer: a randomised, controlled, phase 3 trial. Lancet Oncol 14:88-96.

Hardy KD, Wahlin MD, Papageorgiou I, Unadkat JD, Rettie AE, and Nelson SD (2014) Studies on the role of metabolic activation in tyrosine kinase inhibitor-dependent hepatotoxicity: induction of CYP3A4 enhances the cytotoxicity of lapatinib in HepaRG cells. Drug Metab Dispos $\mathbf{4 2}$ $162-171$.

Hesselink DA, van Schaik RH, van der Heiden IP, van der Werf M, Gregoor PJ, Lindemans J, Weimar W, and van Gelder T (2003) Genetic polymorphisms of the CYP3A4, CYP3A5, and MDR-1 genes and pharmacokinetics of the calcineurin inhibitors cyclosporine and tacrolimus. Clin Pharmacol Ther 74:245-254.

Ho HK, Chan JC, Hardy KD, and Chan EC (2015) Mechanism-based inactivation of CYP450 enzymes: a case study of lapatinib. Drug Metab Rev 47:21-28.

Huang W, Lin YS, McConn DJ II, Calamia JC, Totah RA, Isoherranen N, Glodowski M, and Thummel KE (2004) Evidence of significant contribution from CYP3A5 to hepatic drug metabolism. Drug Metab Dispos 32:1434-1445.

Hustert E, Haberl M, Burk O, Wolbold R, He YQ, Klein K, Nuessler AC, Neuhaus P, Klattig J, Eiselt R, et al. (2001) The genetic determinants of the CYP3A5 polymorphism. Pharmacogenetics 11:773-779.

Klees TM, Sheffels P, Thummel KE, and Kharasch ED (2005) Pharmacogenetic determinants of human liver microsomal alfentanil metabolism and the role of cytochrome P450 3A5. Anes thesiology 102:550-556.

Klein K and Zanger UM (2013) Pharmacogenomics of cytochrome P450 3A4: recent progress toward the "missing heritability" problem. Front Genet 4:1-15.

Kuehl P, Zhang J, Lin Y, Lamba J, Assem M, Schuetz J, Watkins PB, Daly A, Wrighton SA, Hall $\mathrm{SD}$, et al. (2001) Sequence diversity in CYP3A promoters and characterization of the genetic basis of polymorphic CYP3A5 expression. Nat Genet 27:383-391.

Lackey KE (2006) Lessons from the drug discovery of lapatinib, a dual ErbB1/2 tyrosine kinase inhibitor. Curr Top Med Chem 6:435-460.

Lamba JK, Lin YS, Schuetz EG, and Thummel KE (2002) Genetic contribution to variable human CYP3A-mediated metabolism. Adv Drug Deliv Rev 54:1271-1294.
Lamba V, Panetta JC, Strom S, and Schuetz EG (2010) Genetic predictors of interindividual variability in hepatic CYP3A4 expression. $J$ Pharmacol Exp Ther 332:1088-1099.

Li X, Jeso V, Heyward S, Walker GS, Sharma R, Micalizio GC, and Cameron MD (2014) Characterization of T-5 $\mathrm{N}$-oxide formation as the first highly selective measure of CYP3A5 activity. Drug Metab Dispos 42:334-342.

Li X, Song X, Kamenecka TM, and Cameron MD (2012) Discovery of a highly selective CYP3A4 inhibitor suitable for reaction phenotyping studies and differentiation of CYP3A4 and CYP3A5. Drug Metab Dispos 40:1803-1809.

Lin YS, Dowling AL, Quigley SD, Farin FM, Zhang J, Lamba J, Schuetz EG, and Thummel KE (2002) Co-regulation of CYP3A4 and CYP3A5 and contribution to hepatic and intestinal midazolam metabolism. Mol Pharmacol 62:162-172.

Lu Y, Fuchs EJ, Hendrix CW, and Bumpus NN (2014) CYP3A5 genotype impacts maraviroc concentrations in healthy volunteers. Drug Metab Dispos 42:1796-1802.

Lu Y, Hendrix CW, and Bumpus NN (2012) Cytochrome P450 3A5 plays a prominent role in the oxidative metabolism of the anti-human immunodeficiency virus drug maraviroc. Drug Metab Dispos 40:2221-2230.

Moy B, Kirkpatrick P, Kar S, and Goss P (2007) Lapatinib. Nat Rev Drug Discov 6:431-432.

Moy B, Rappold E, Williams L, Kelly T, Nicolodi L, Maltzman JD, and Goss PE (2009) Hepatobiliary abnormalities in patients with metastatic cancer treated with lapatinib. J Clin Oncol 27 (Suppl 15):1043-1043

Parham LR, Briley LP, Li L, Shen J, Newcombe PJ, King KS, Slater AJ, Dilthey A, Iqbal Z, McVean G, et al. (2016) Comprehensive genome-wide evaluation of lapatinib-induced liver injury yields a single genetic signal centered on known risk allele HLA-DRB1*07:01. Phar macogenomics $J$ 16:180-185.

Peroukides S, Makatsoris T, Koutras A, Tsamandas A, Onyenadum A, Labropoulou-Karatza C, and Kalofonos H (2011) Lapatinib-induced hepatitis: a case report. World J Gastroenterol 17: 2349-2352.

Polli JW, Humphreys JE, Harmon KA, Castellino S, O’Mara MJ, Olson KL, John-Williams LS, Koch KM, and Serabjit-Singh CJ (2008) The role of efflux and uptake transporters in [N-\{3-chloro-4-[(3fluorobenzyl)oxy]phenyl\}-6-[5-(\{[2-(methylsulfonyl)ethyl]amino $\}$ methyl)-2-furyl]-4-quinazolinamine (GW572016, lapatinib) disposition and drug interactions. Drug Metab Dispos 36:695-701.

Roy SK, Korzekwa KR, Gonzalez FJ, Moschel RC, and Dolan ME (1995) Human liver oxidative metabolism of O6-benzylguanine. Biochem Pharmacol 50:1385-1389.

Rusnak DW, Affleck K, Cockerill SG, Stubberfield C, Harris R, Page M, Smith KJ, Guntrip SB, Carter MC, Shaw RJ, et al. (2001) The characterization of novel, dual ErbB-2/EGFR, tyrosine kinase inhibitors: potential therapy for cancer. Cancer Res 61:7196-7203.

Schaid DJ, Spraggs CF, McDonnell SK, Parham LR, Cox CJ, Ejlertsen B, Finkelstein DM, Rappold E, Curran J, Cardon LR, et al. (2014) Prospective validation of HLA-DRB1*07:01 allele carriage as a predictive risk factor for lapatinib-induced liver injury. J Clin Oncol 32:2296-2303.

Sorich MJ, Mutlib F, van Dyk M, Hopkins AM, Polasek TM, Marshall JC, Rodrigues AD, and Rowland A (2019) Use of physiologically based pharmacokinetic modeling to identify physiological and molecular characteristics driving variability in axitinib exposure: a fresh approach to precision dosing in oncology. J Clin Pharmacol 59:872-879.

Spraggs CF, Budde LR, Briley LP, Bing N, Cox CJ, King KS, Whittaker JC, Mooser VE, Preston AJ, Stein SH, et al. (2011) HLA-DQA $1 * 02: 01$ is a major risk factor for lapatinib-induced hepatotoxicity in women with advanced breast cancer. J Clin Oncol 29:667-673.

Spraggs CF, Parham LR, Hunt CM, and Dollery CT (2012) Lapatinib-induced liver injury characterized by class II HLA and Gilbert's syndrome genotypes. Clin Pharmacol Ther 91:647-652.

Takakusa H, Wahlin MD, Zhao C, Hanson KL, New LS, Chan ECY, and Nelson SD (2011) Metabolic intermediate complex formation of human cytochrome P450 3A4 by lapatinib. Drug Metab Dispos 39:1022-1030.

Teng WC, Oh JW, New LS, Wahlin MD, Nelson SD, Ho HK, and Chan ECY (2010) Mechanismbased inactivation of cytochrome P450 3A4 by lapatinib. Mol Pharmacol 78:693-703.

Teo YL, Saetaew M, Chanthawong S, Yap YS, Chan EC, Ho HK, and Chan A (2012) Effect of CYP3A4 inducer dexamethasone on hepatotoxicity of lapatinib: clinical and in vitro evidence. Breast Cancer Res Treat 133:703-711.

Towles JK, Clark RN, Wahlin MD, Uttamsingh V, Rettie AE, and Jackson KD (2016) Cytochrome P450 3A4 and CYP3A5-catalyzed bioactivation of lapatinib. Drug Metab Dispos 44:1584-1597. Tseng E, Fate GD, Walker GS, Goosen TC, and Obach RS (2018) Biosynthesis and Identification of metabolites of maraviroc and their use in experiments to delineate the relative contributions of cytochrome P4503A4 versus 3A5. Drug Metab Dispos 46:493-502.

Tseng E, Walsky RL, Luzietti RA Jr, Harris JJ, Kosa RE, Goosen TC, Zientek MA, and Obach RS (2014) Relative contributions of cytochrome CYP3A4 versus CYP3A5 for CYP3A-cleared drugs assessed in vitro using a CYP3A4-selective inactivator (CYP3cide). Drug Metab Dispos 42:1163-1173.

Walsky RL and Obach RS (2004) Validated assays for human cytochrome P450 activities. Drug Metab Dispos 32:647-660.

Walsky RL, Obach RS, Hyland R, Kang P, Zhou S, West M, Geoghegan KF, Helal CJ, Walker GS, Goosen TC, et al. (2012) Selective mechanism-based inactivation of CYP3A4 by CYP3cide (PF04981517) and its utility as an in vitro tool for delineating the relative roles of CYP3A4 versus CYP3A5 in the metabolism of drugs. Drug Metab Dispos 40:1686-1697.

Wang D, Guo Y, Wrighton SA, Cooke GE, and Sadee W (2011) Intronic polymorphism in CYP3A4 affects hepatic expression and response to statin drugs. Pharmacogenomics $J$ 11:274-286.

Wang D and Sadee W (2016) CYP3A4 intronic SNP rs35599367 (CYP3A4*22) alters RNA splicing. Pharmacogenet Genomics 26:40-43.

Wrighton SA and Stevens JC (1992) The human hepatic cytochromes P450 involved in drug metabolism. Crit Rev Toxicol 22:1-21.

Yang X, Zhang B, Molony C, Chudin E, Hao K, Zhu J, Gaedigk A, Suver C, Zhong H, Leeder JS, et al. (2010) Systematic genetic and genomic analysis of cytochrome P450 enzyme activities in human liver. Genome Res 20:1020-1036.

Zanger UM and Schwab M (2013) Cytochrome P450 enzymes in drug metabolism: regulation of gene expression, enzyme activities, and impact of genetic variation. Pharmacol Ther 138:103-141 Zientek MA, Goosen TC, Tseng E, Lin J, Bauman JN, Walker GS, Kang P, Jiang Y, Freiwald S, Neul D, et al. (2016) In vitro kinetic characterization of axitinib metabolism. Drug Metab Dispos 44:102-114.

Address correspondence to: Dr. Klarissa D. Jackson, UNC Eshelman School of Pharmacy, University of North Carolina at Chapel Hill, 3320 Kerr Hall, CB\# 7569, Chapel Hill, NC 27599-7569. E-mail: klarissa.jackson@unc.edu 